\title{
Southwest Regional Partnership on Carbon Sequestration
}

\author{
Semiannual Report \\ Reporting Period: May 1, 2004 - September 30, 2004 \\ Principal Author*: Brian McPherson
}

Issue Date: November, 2004

DE-PS26-03NT41983

Submitting Organization: New Mexico Institute of Mining and Technology 801 Leroy Place

Socorro, New Mexico 87801

*Other Contributing Authors:

Rick Allis, Utah Geological Survey, Barry Biediger, Utah Automated Geographical Reference Center, Joel Brown, U.S. Department of Agriculture, Jim Cappa, Colorado Geological Survey, George Guthrie, Los Alamos National Laboratory, Richard Hughes, University of Oklahoma, Eugene Kim, Texas Bureau of Economic Geology, Robert Lee, New Mexico Institute of Mining and Technology, Dennis Leppin, Gas Technology Institute, Charles Mankin, Oklahoma Geological Survey, Orman Paananen, Sandia National Laboratories, Rajesh Pawar, Los Alamos National Laboratory, Tarla Peterson, University of Utah, Steve Rauzi, Arizona Geological Survey, Jerry Stuth, Texas A\&M University, Genevieve Young, Colorado Geological Survey, and many other partners in the Southwest Partnership 


\section{Disclaimer}

This report was prepared as an account of work sponsored by an agency of the United States Government. Neither the United States Government nor any agency thereof, nor any of their employees, makes any warranty, express or implied, or assumes any legal liability or responsibility for the accuracy, completeness, or usefulness of any information, apparatus, product, or process disclosed, or represents that its use would not infringe privately owned rights. Reference herein to any specific commercial product, process, or service by trade name, trademark, manufacturer, or otherwise does not necessarily constitute or imply its endorsement, recommendation, or favoring by the United States Government or any agency thereof. The views and opinions of authors expressed herein do not necessarily reflect those of the United States Government or any agency thereof. 


\begin{abstract}
The Southwest Partnership Region includes six whole states, including Arizona, Colorado, Kansas, New Mexico, Oklahoma, and Utah, roughly one-third of Texas, and significant portions of adjacent states. The Partnership comprises a large, diverse group of expert organizations and individuals specializing in carbon sequestration science and engineering, as well as public policy and outreach. The main objective of the Southwest Partnership project is to achieve an 18\% reduction in carbon intensity by 2012. The Partnership made great progress in this first year. Action plans for possible Phase II carbon sequestration pilot tests in the region are almost finished, including both technical and non-technical aspects necessary for developing and carrying out these pilot tests. All partners in the Partnership are taking an active role in evaluating and ranking optimum sites and technologies for capture and storage of $\mathrm{CO}_{2}$ in the Southwest Region. We are identifying potential gaps in all aspects of potential sequestration deployment issues.
\end{abstract}




\section{Table of Contents}

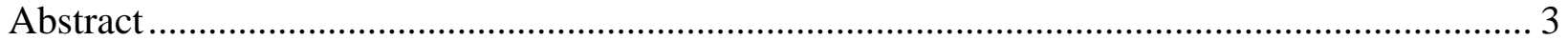

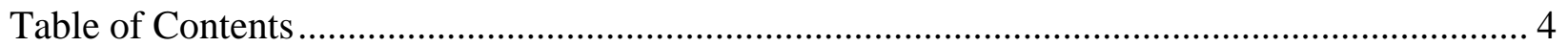

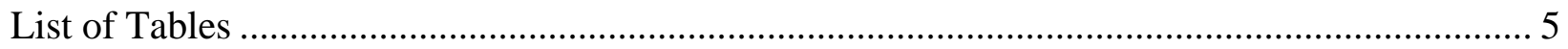

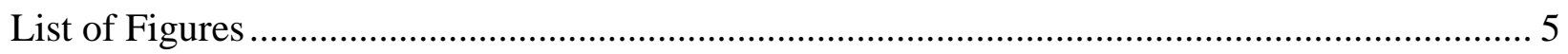

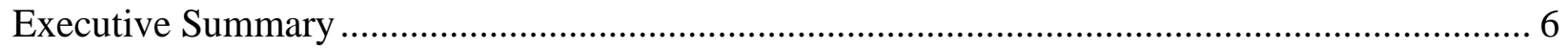

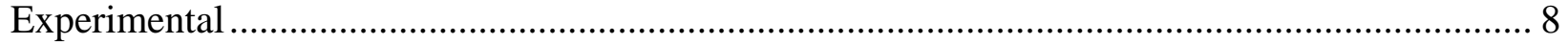

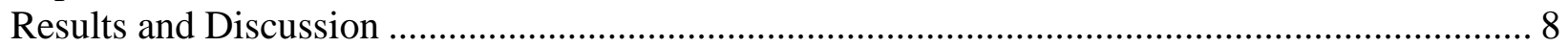

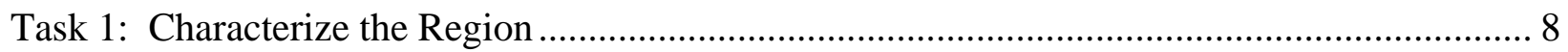

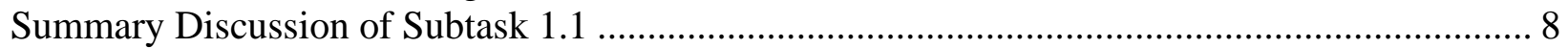

Summary of $\mathrm{CO}_{2}$ Source Data for the Southwest Region .................................................. 8

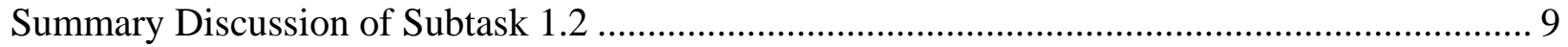

Summary of Terrestrial Carbon Capacity for the Southwest Region ......................................... 9

Summary of Geologic and Mineralization Sink Options for the Southwest Region.................... 11

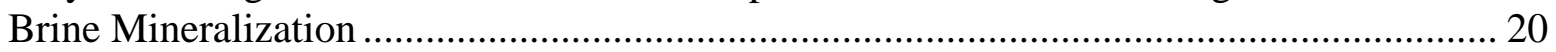

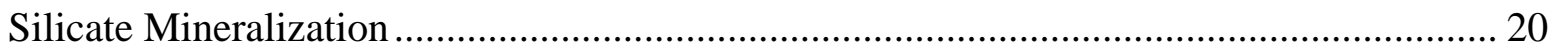

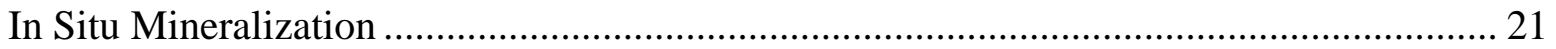

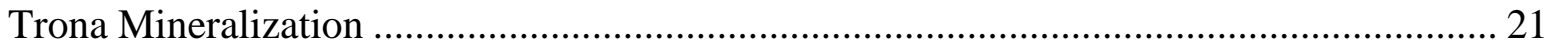

Summary Discussion of Subtask 1.3: Separation and Capture Technologies Employed in the

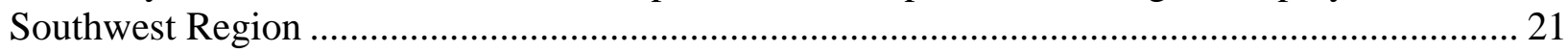

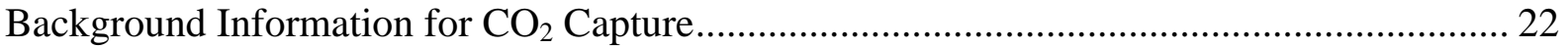

Brief Summary of Database Associated with Subtask 1.4: Description of GIS Database

Developed and Implemented by the Southwest Partnership................................................ 37

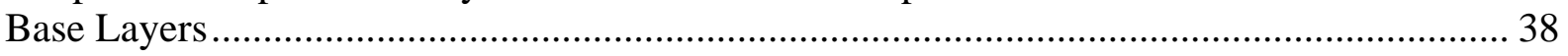

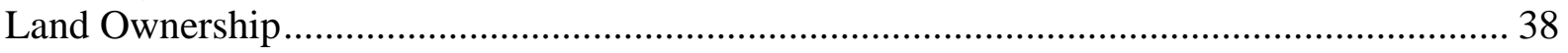

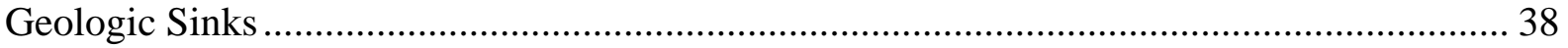

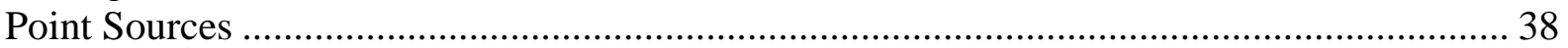

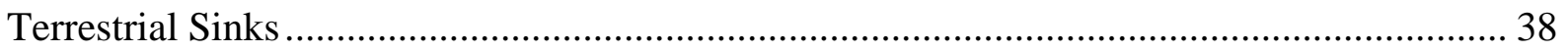

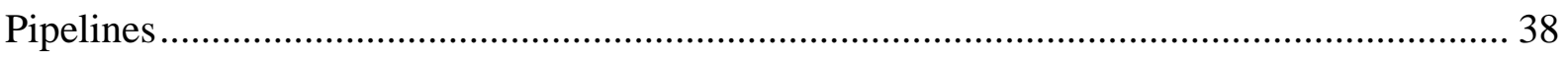

Task 2: Identify and Address Sequestration Implementation Issues ...................................... 39

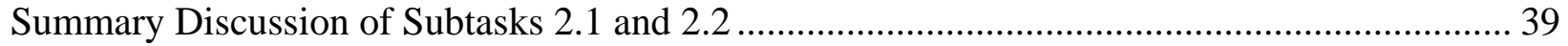

Summary of Regulatory and Permitting Requirements for Sequestration in Southwest Region . 39

Summary of Risk Assessment for Potential Geologic Sequestration Sites ............................... 39

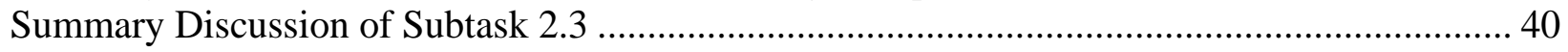

Summary of Year 1 Measuring/Monitoring/Verification (MMV) Efforts ........................... 40

Summary Discussion of Subtask 2.4: Action Plan for Addressing Environmental Efficacy and General Sequestration Implementation Requirements: Integrated Assessment Approach.......... 43

Task 3: Assess and Initiate Public Outreach/Acceptance ..................................................... 47

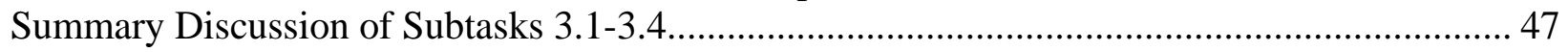

Summary Report of Year 1 Outreach Efforts ....................................................................... 47

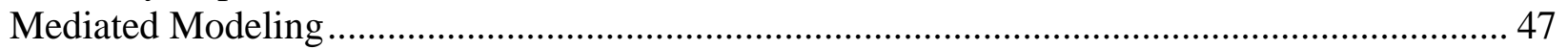

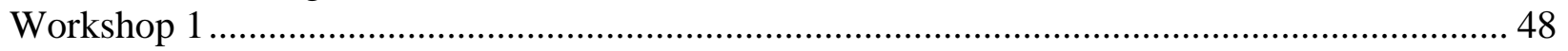

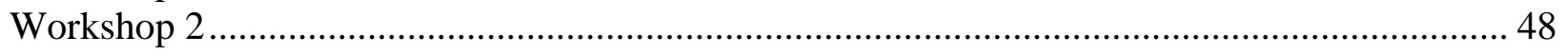

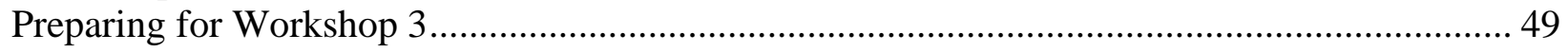

Task 4: Identify and Rank Sequestration Options for the Southwest Region............................. 51

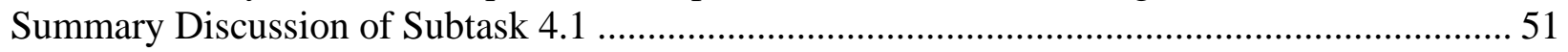


Summary of Year 1 Integrated Assessment Analysis................................................................... 51

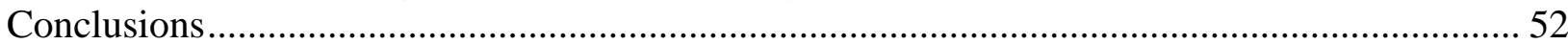

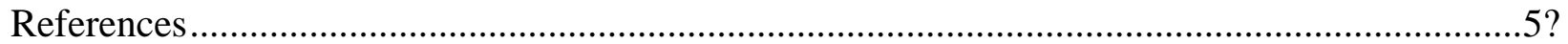

\section{List of Tables}

Table 1. Data Collection Agencies by State ...................................................................................11

Table 2. Forecasted Carbon Sequestration Capacity for Colorado

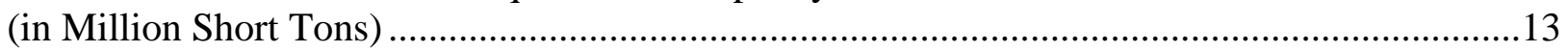

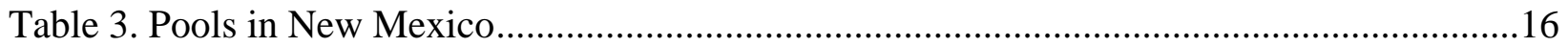

\section{List of Figures}

Figure 1. Map of Southwest Region that indicates locations of potential

Phase II pilot test sites............................................................................................................

Figure 2. Fossil fuel carbon dioxide emissions for Utah and the overall U.S. Sources: accessible in the Southwest Regional Partnership database and in the original source,

http://www.energy.utah.gov/ghgpage.htm................................................................................

Figure 3. General outline of potential study areas in Colorado. ...............................................12

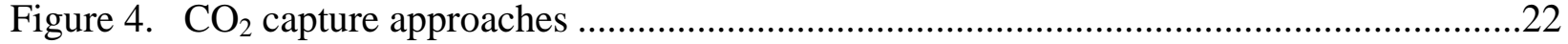

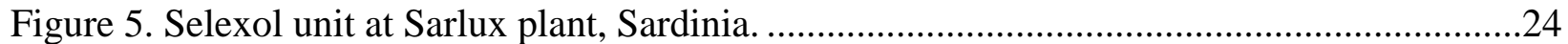

Figure 6. Process flow diagram for the Econamine FG process ......................................................25

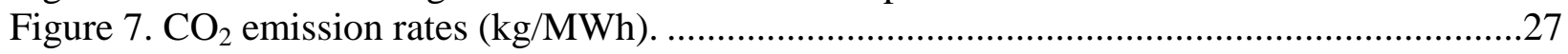

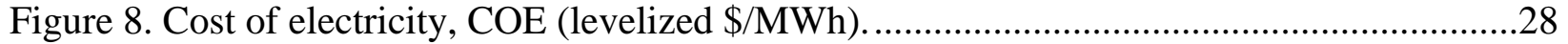

Figure 9. Cost of $\mathrm{CO}_{2}$ avoided (\$/tonne $\mathrm{CO}_{2}$ )......................................................................29

Figure 10. Carbon capture projects from the IEA Greenhouse Gas Programme database.......30-34

Figure 11. Commercial scale carbon capture projects from the IEA Greenhouse

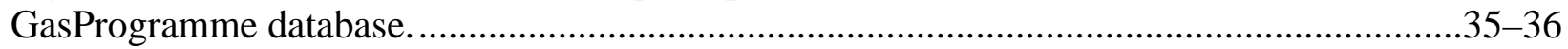

Figure 12. Sequestration model basic structure. ..........................................................................44

Figure 13. Map of test area showing general features, as indicated (this is an actual screen shot from the database interface screen). 


\section{Executive Summary}

The Southwest Partnership Region on Carbon Sequestration includes six whole states, including Arizona, Colorado, Kansas, New Mexico, Oklahoma, and Utah, roughly one third of Texas, including the panhandle, the Permian basin and surrounding region, and significant portions of adjacent states, including southern Wyoming and eastern Nevada. This region is energy-rich and possesses among the largest growth rates in the nation. Additionally, it is unique in that it contains two major $\mathrm{CO}_{2}$ pipeline networks that transport over 30 million tons/year of natural subsurface $\mathrm{CO}_{2}$ from southern Colorado and northern New Mexico to petroleum fields in other parts of the region, in particular the Permian basin, for enhanced oil recovery. The 10 largest coal-fired power plants in the region produce 50\%-roughly 140 million tons-of $\mathrm{CO}_{2} /$ year, of the total $\mathrm{CO}_{2}$ from power-plant fossil fuel combustion, and power plant emissions approach half the total $\mathrm{CO}_{2}$ emissions. The main objective of the Southwest Partnership project is to achieve an $18 \%$ reduction in carbon intensity by 2012 . For example, one of the partnership's specific goals is to reduce the region's greenhouse-gas (GHG) intensity to less than 182 metric tons carbon equivalent/gross state product (\$million). This Phase I project is designed to provide optimum preparation and action plans for reducing the region’s GHG intensity.

The Southwest Regional Partnership comprises a large, diverse group of expert organizations and individuals specializing in carbon sequestration science and engineering, as well as public policy and outreach. These partners include 21 state government agencies and universities, the five major electric utility industries, seven oil, gas and coal companies, three federal agencies, the Navajo Nation, several NGOs including the Western Governors Association, and several collaborative data-sharing agreements with surrounding states and with the other NETLsponsored Partnerships. The Southwest Partnership team has assembled itself into working groups that reflect the main tasks necessary for achieving the goal of reduced GHG intensity: (1) Data, Information and GIS/Database Group, (2) Public Education and Involvement Group, (3) Regulatory Compliance Group, (4) Transportation/Infrastructure/ $\mathrm{CO}_{2}$ Point Sources and $\mathrm{CO}_{2}$ Separation and Capture Group, (5) $\mathrm{CO}_{2}$ Sinks and Distributed Sources Group, and (6) the Integrated Assessment Group.

The Partnership made great progress in this first year. Action plans for possible Phase II carbon sequestration pilot tests in the region are almost finished, including both technical and non-technical aspects necessary for developing and carrying out these pilot tests. The Partnership has assembled a comprehensive database of readily available data regarding $\mathrm{CO}_{2}$ sinks and sources in the region, and continues to gather data that are not readily available but require significant effort to acquire, e.g., from non-digital sources and from private (nonpublished) data sources. The Partnership team has developed and deployed a website network to facilitate storage of these data and information sharing, decision-making, and future management of carbon sequestration in the region. The Partnership has almost finished assembling details of existing regulatory/permitting requirements as well as action plans assessing potential risks and for measurement, monitoring, and verification (MMV) of ultimate sequestration approaches for the region. In addition to the Partnership's website designed for public outreach and education, the Partnership has held several public conferences and "town hall" meetings to educate the public about possible sequestration approaches. All partners in the Partnership are taking an active role working with the Integrated Assessment Group to evaluate and rank the optimum sites and sequestration technologies for capture and storage of $\mathrm{CO}_{2}$ in the Southwest Region. We are identifying potential gaps in all aspects of potential sequestration deployment issues, from 
possible problems with technology and engineering to gaps in regulatory frameworks to potential limitations in existing MMV needed to validate long-term storage efforts.

\section{Phase II Pilot Project Options Under Consideration}

At the end of this first year of the Partnership project, three general areas are being considered for possible Phase II pilot tests, with seven specific sites within these areas. The three general areas are (1) Four Corners area, (2) northern Oklahoma, and (3) the Permian basin in western Texas and eastern New Mexico. The seven specific sites within these areas are illustrated on Figure 1. These seven sites, indicated by number on Figure 1, include:

(1) Aneth Oil/Gas Field, Utah - potential industry partners include Navajo Oil and Gas Company, ExxonMobil and Kinder Morgan. The Partnership is investigating the opportunity for enhanced oil recovery and concomitant geologic sequestration.

(2) San Juan Basin, Four Corners Power Plant or San Juan Power Plant, New Mexico potential partners include Public Service Company of New Mexico (PNM), Arizona Public Service Company (APS), in tandem with the Navajo Nation, already a Partner in the Partnership. The Partnership is investigating potential sequestration in oil/gas reservoirs and/or coalbeds in the San Juan basin below these power plants.

(3) Springerville/St. Johns, Arizona - Site of a natural $\mathrm{CO}_{2}$ storage reservoir - potential partners include Tucson Electric Power (TEP) and Ridgeway Petroleum. The Partnership is investigating the potential of subsurface geologic sequestration associated with $\mathrm{CO}_{2}$ removed from TEP's power plant near Springerville.

(4) Mustang Energy CoalFired Power Plant Project Milan, New Mexico potential industry partner includes Peabody Energy; the focus of this power plant initiative is scrubbing of flue gas to remove sulfur dioxides, nitrogen oxides, mercury, and carbon dioxide. The Partnership is investigating potential subsurface injection of the scrubbed $\mathrm{CO}_{2}$ and deploying extensive MMV.

(5) and (6) an ammonia plant near Enid, Oklahoma offers an interesting and unique possibility for

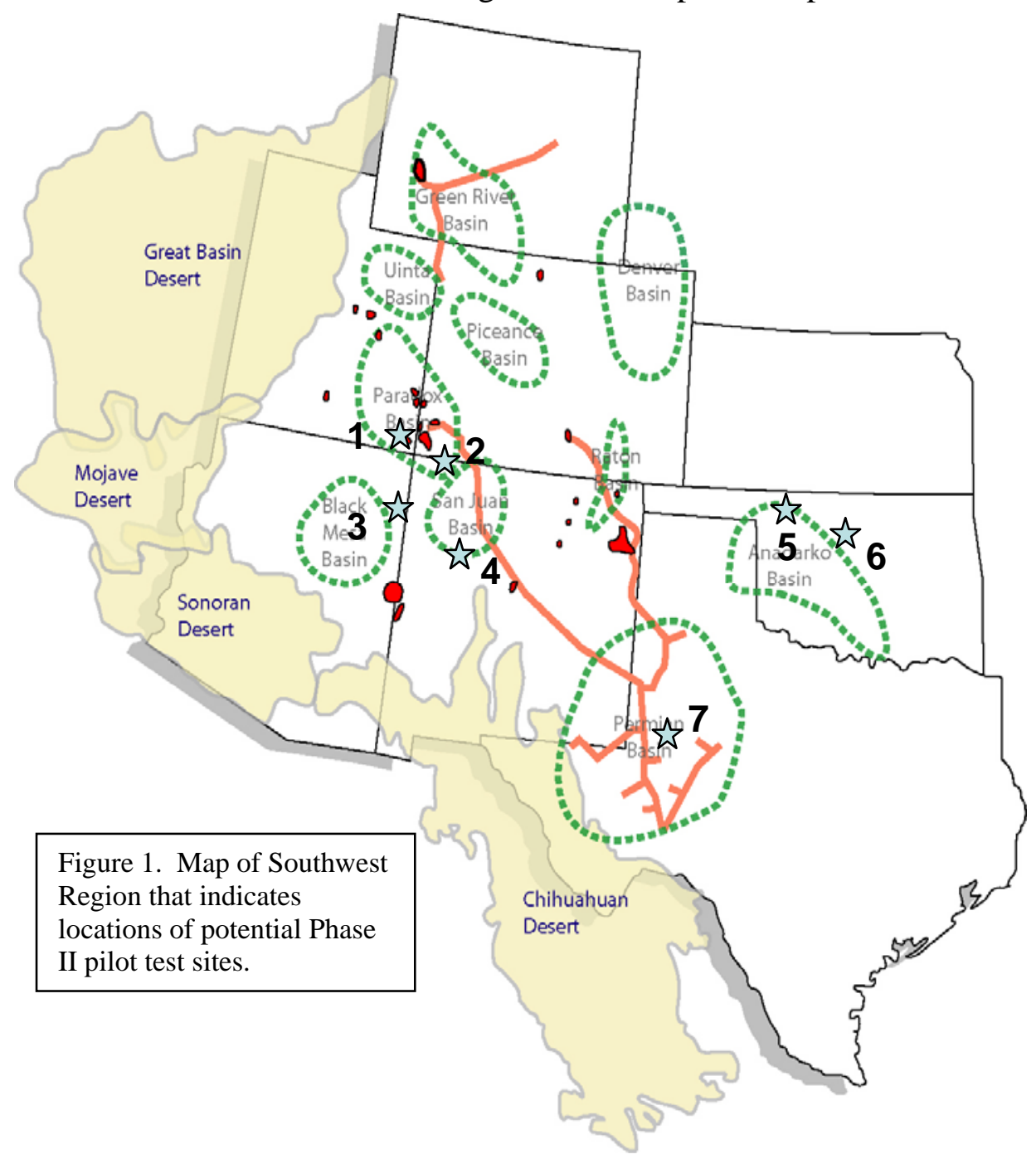


geologic sequestration, as does an aquifer sequestration possibility near Freedom, Oklahoma. Potential industry partners include the Beard Company.

(7) SACROC Field, Permian basin, west TX - Kinder Morgan is almost finished building a new power plant near Snyder, TX, and is planning to attach amine-based $\mathrm{CO}_{2}$ capture units to the plant, providing an opportunity for a pilot that includes separation and capture, injection, and extensive MMV. Potential industry partners include Kinder Morgan, Statoil, and others.

\section{Experimental}

No special experimental methods are being employed in this project. Materials and equipment used include only standard communication means and data management tools, including computerized databases, internet websites, etc.

\section{Results and Discussion}

The first year results of this project are described in this section, which is split into four subsections, one for each of the major tasks of the Partnership Phase I project. In each subsection we detail the current status of each major task.

\section{Task 1: Characterize the Region}

\section{Summary Discussion of Subtask 1.1}

\section{Summary of $\mathrm{CO}_{2}$ Source Data for the Southwest Region}

The Regional Partnerships for Carbon Sequestration programs funded by DOE are ultimately required to identify the best carbon sequestration options in their respective regions, consisting of a $\mathrm{CO}_{2}$ source, applicable $\mathrm{CO}_{2}$ capture technology, transportation logistics (if applicable) and destination formation for non-terrestial sequestration approaches. In most cases the carbon capture step is the most costly, and selecting the appropriate least-cost options will be of particular importance.

GTI was selected to provide advice and consultation on capture technologies for the Southwest Partnership. This report consists of a summary of various databases assembled to help locate and quantify the $\mathrm{CO}_{2}$ emissions in the Southwest Region. These point sources in the southwest region are mainly coal-fired power plants. Other sources include natural gas processing plants, refineries, ammonia/fertilizer production, ethylene and ethanol plants, and cement plants. This information will assist in identifying candidate projects for Phase II.

Scope of Work: The objective of this portion of the Southwest Partnership project is to delineate technologies applicable to capturing carbon dioxide from point sources and to provide estimates from various sources of the specific costs of such technologies. Research and Development on new technologies are reviewed and a listing of those that appear promising and are sufficiently in the development cycle will be presented.

Databases: GTI was requested to assemble a listing of gas treating plants in the Southwest Partnership Region (SW). These are plants that remove $\mathrm{CO}_{2}$ from natural gas and generally emit the $\mathrm{CO}_{2}$ at low pressure into the atmosphere. These were assembled and transmitted. However, the original data did not contain any location beyond the state in which the plant was located. GTI was requested to provide any and all location data as well as emission data in addition to facility data required to estimate the cost of capture. Over 40 databases were assembled to meet the source data needs of the partnership, and these data are integrated into the main Partnership 
database. Some of the databases exist as Microsoft ${ }^{\circledR}$ AccessTM databases, but all are also assembled into Microsoft ${ }^{\circledR}$ ExcelTM files to ease transfer and portability for the range of applications required.

An example of source data available is illustrated in Figure 2, which includes national emissions as well as those for the state of Utah.

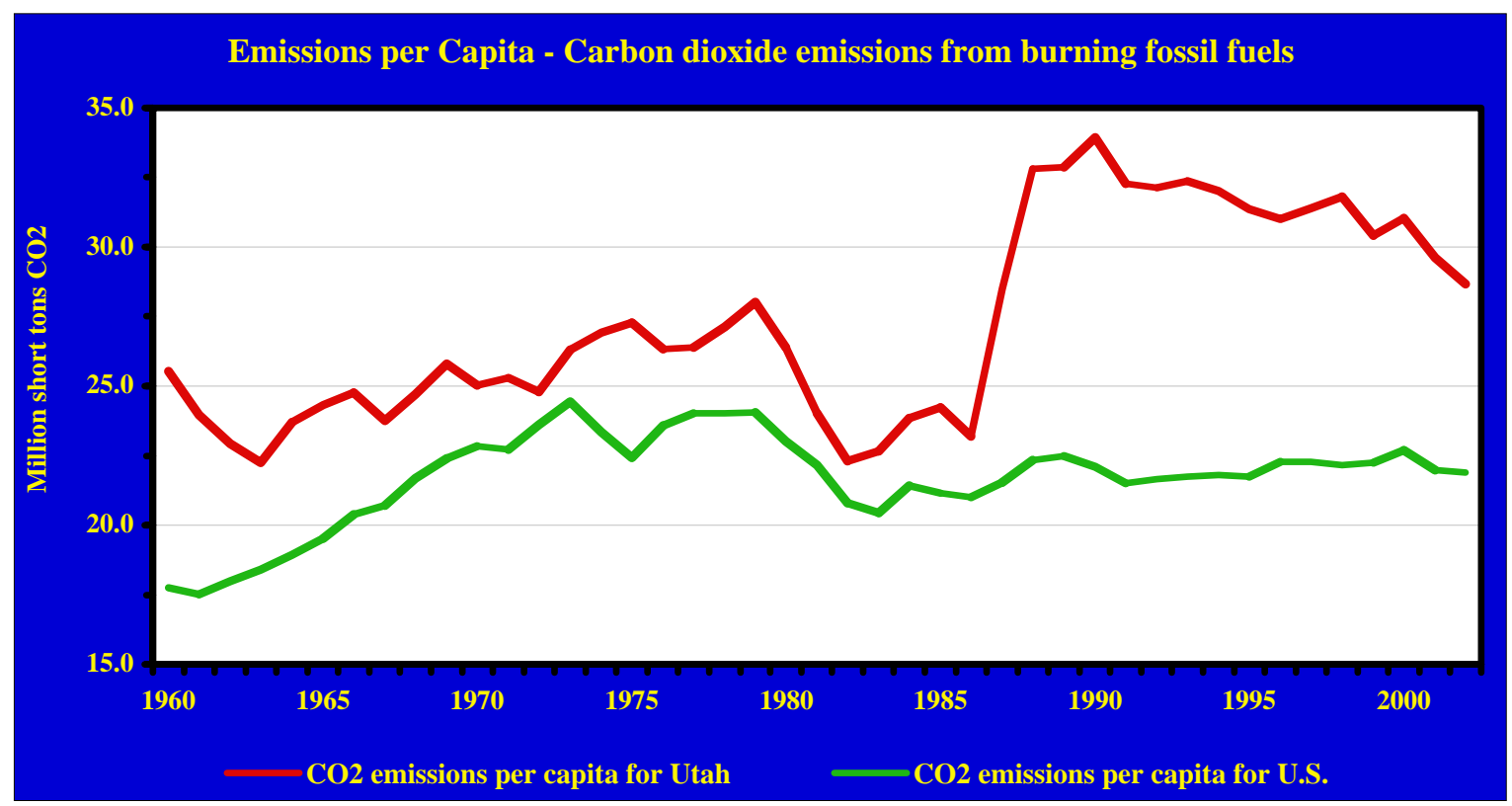

Figure 2. Fossil fuel carbon dioxide emissions for Utah and the overall U.S. Sources: accessible in the Southwest Regional Partnership database and in the original source, http://www.energy.utah.gov/ghgpage.htm.

\section{Summary Discussion of Subtask 1.2}

\section{Summary of Terrestrial Carbon Capacity for the Southwest Region}

The terrestrial assessment team approached the problem of estimating potential carbon storage by organizing existing information from a variety of sources. Soils, climate, land cover, land use and land management information were organized into a geographic data base with validity at the Major Land Resource Area (MLRA) level. Within each MLRA, the distribution of management practices and land use patterns by broad soil type was examined to determine potential to increase carbon storage in the soil and vegetation and to identify areas where land degradation represents a risk of loss of currently stored carbon. The results of the subregional analysis were interpreted within the context of two major assumptions: a) land use is unlikely to change solely in response to incentives (public or private) to sequester carbon and b) existing government conservation programs offer the most cost-effective means of increasing carbon storage and reducing risk of loss at the regional scale.

Terrestrial sequestration in the Southwest region is naturally limited by low average annual precipitation and the interannual variability in precipitation. Increases in soil and vegetation carbon are the result of precipitation-driven carbon assimilation by plants and subsequent storage in stable compounds in the soil or as wood. Even in systems managed for carbon storage, wet years followed by a series of dry years may result in a net carbon flux from the system. 
Overcoming the natural variability in rain fed agricultural systems and forests requires increasing the acreage managed for increased carbon storage region-wide as opposed to intensive management of smaller project-scale areas.

There are substantial opportunities to increase carbon storage in terrestrial ecosystems and achieve high environmental co-benefits. Improved fuel management in conifer forests can lower risk of carbon loss to catastrophic wildfire and improve wildlife habitat and watershed hydrology. These forests are primarily federal land so fuel and forest management plans are in place. The majority of forest stand practices are well known and proven to be reliable both in terms of carbon sequestration and co-benefits. Small acreages of private forest land can be improved using programs like the Forestry Incentives Program and Stewardship Incentives Program administered through the USDA. There is little opportunity to enhance sequestration in forestlands through large scale private sequestration projects. Tribal and other privately held forest lands are primarily semi-industrial and have limited capacity to store carbon beyond their current levels.

Increasing soil carbon storage on private croplands also offers realistic opportunities to capture multiple benefits. In the eastern portion of the region, much of the rain-fed cropland is dedicated to wheat or wheat-based rotations. While the adoption of reduced tillage is relatively widespread throughout the area, less than $50 \%$ of the cropland is farmed using minimum tillage techniques consistently. To achieve full benefits, reduced tillage practices need to be applied consistently year to year. Sequestration potential on these croplands varies between 0.1 and 0.5 $\mathrm{T} / \mathrm{ha} / \mathrm{y}$. Conservation practices are relatively well-proven and conservation programs such as Environmental Quality Incentives Program, Conservation Reserve Program and Conservation Security Program offer financial and technical assistance to farmers and ranchers to implement practices. There is little opportunity to increase storage on irrigated land (either sprinkler or flood) because of the intensity of land use and the types of crops grown.

Land currently enrolled in the Conservation Reserve Program (converting cropland to perennial vegetation) has the potential to be a significant source of carbon emissions if conversion back to cropland is widespread when the contract period ends. Most of the lands enrolled in this program is at equilibrium now, so there is little opportunity to sequester carbon. Bringing new acres into the program is also likely to have limited impact since program funds are shrinking and land enrollment has probably peaked.

Likewise, there is limited opportunity to dramatically increase carbon storage on rangelands throughout the region, since most areas are at a relatively stable equilibrium given land use history and management. The challenge on these lands is to maintain relatively large amounts of soil carbon stocks in the soil in the face of advancing degradation and environmental fluctuations. Much of the desert grassland and shrubland areas with less than 12 in. precipitation annually is subject to loss of cover and exposure to wind and water erosion as a result of historical management practices. Retaining soil carbon levels in these ecosystems will require active restoration practices that are risky and unreliable given the current technologies. More mesic grasslands in the eastern portion of the region are likely at equilibrium since there has been limited soil disturbance in the past century. The challenge in more mesic areas is to maintain soil carbon stocks in the face of potentially degrading erosion as a result of increased shrub cover.

Information for making relatively accurate estimates of potential storage and emissions in terrestrial systems is available. However, the lack of a dedicated region-wide monitoring system that tracks land use changes relatively fine spatial scales is a serious handicap. Any serious 
effort to increase the amount of carbon stored in terrestrial ecosystems must include a robust and flexible land use and land management monitoring network.

Summary of Geologic and Mineralization Sink Options for the Southwest Region

The tasks of the geologic sink characterization sub team were as follows:

- Identify geologic sink options in the region

- Identify distribution, nature and size of potential sites

- Identify type of data necessary for characterization

- Identify sources of data

- Data collection and compilation

- Analyze the data to rank geologic options

The early focus of the sink characterization team was to define the data needs, data formats and data compilation protocols. Prior to beginning the data collection and compilation effort, protocols for data transfers to GIS database were determined in discussions with the GIS team. In addition, types of GIS data needed and appropriate formats for each data were also determined. During these discussions it was determined that the data for the partnership would be collected in the GASIS database format. The format was provided to individual states to facilitate the data collection effort. Approximately 321 attributes were identified to suitably capture the information for individual fields. As the number of geologic sinks is significantly large in the region, it was decided that only fields with over 1 million barrels (bbls) oil or 10 bcf of gas production would be considered for further analyses. The data collection process and subsequent database update was performed by the various state agencies participating in the project (Table 1).

Table 1. Data Collection Agencies by State

\begin{tabular}{|c|c|}
\hline State & Data Collection Agency \\
\hline Arizona & Arizona Geological Survey \\
\hline Colorado & Colorado Geological Survey \\
\hline New Mexico & New Mexico Geological Survey \\
\hline Oklahoma & University of Oklahoma \\
\hline Utah & Utah Geological Survey \\
\hline
\end{tabular}

Each of the agencies used multiple sources of data to characterize the sinks within their state boundaries. The description below summarizes the effort for each of the five states.

Arizona: Geophysical logs, including stratigraphic, mud, spontaneous potential, electrical conductance, gamma, neutron, and porosity logs were scanned and digital files created from oil and gas production/exploratory well files within Arizona. Approximately 2350 logs were scanned from 1095 wells. Data sources include:

- Four Corners Geological Society “Oil and Gas Fields of the Four Corners Area” V1, 1978.

- Oil \& Gas Conservation Commission (OGCC) well permit files, provided by Steve Rauzi, AZGS, Arizona OGCC administrator.

- AZGS Open File reports, bulletins, circulars, and Geologic Maps. 
- United States Geological Survey Open File reports, Professional Papers, and Geologic Investigations.

- Arizona Department of Water Resources Groundwater Site Index and Wells 55 databases.

The GASIS database was populated with 14 oil and gas fields located within Arizona. Of the 14 fields, 10 are gas related and include fields with associated as well as non-associated (He) gas. In addition to the oil and gas fields, 12 deep and seven tertiary saline reservoirs were added to GASIS as potential $\mathrm{CO}_{2}$ sequestration targets. These sites were selected for their proximity to $\mathrm{CO}_{2}$ stationary point sources. Files of deep oil \& gas wells were reviewed to obtain available information for these basins. Saline reservoirs cover a significantly larger area than the welldefined oil and gas fields located in northeast Arizona, and could potentially sequester significantly larger volumes of $\mathrm{CO}_{2}$. Given the limited characterization information, greater uncertainty exists in terms of porosity extent and trap efficiency in these basins. Thus, we have provided candidate reservoirs in close proximity to point sources in Arizona. We are continuing to add information on these basins as it is captured. Coalbed methane sequestration resources were evaluated within the state. None of the deposits met the minimum depth requirement for maintaining $\mathrm{CO}_{2}$ at a critical state.

$\mathrm{CO}_{2}$ point source locations, oil and gas fields, reservoir polygonal coverages, and associated GIS data files were provided to the partnership for inclusion in the Partnership interactive map located on the web site. Data sources included the AZGS depth to bedrock and surface geology maps.

Colorado: Although $\mathrm{CO}_{2}$ sink potential is widely distributed across the state, data collection focused on seven primary study areas (Figure 3 ).

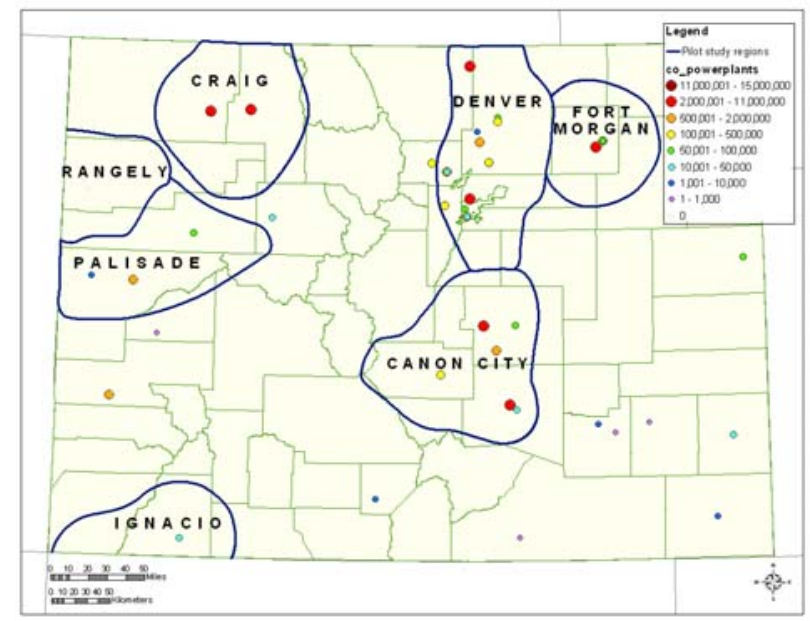

Figure 3. General outline of potential study areas in Colorado.

These areas were defined based on the maximum diversity in potential sequestration options within relatively close proximity to $\mathrm{CO}_{2}$ sources; that is, within a 30 to 40 mile radial distance of one or more power plants. Table 2 summarizes the $\mathrm{CO}_{2}$ emissions for 1999 and potential capacity for each of these seven study areas. 
Table 2. Forecasted Carbon Sequestration Capacity for Colorado (in Million Short Tons)

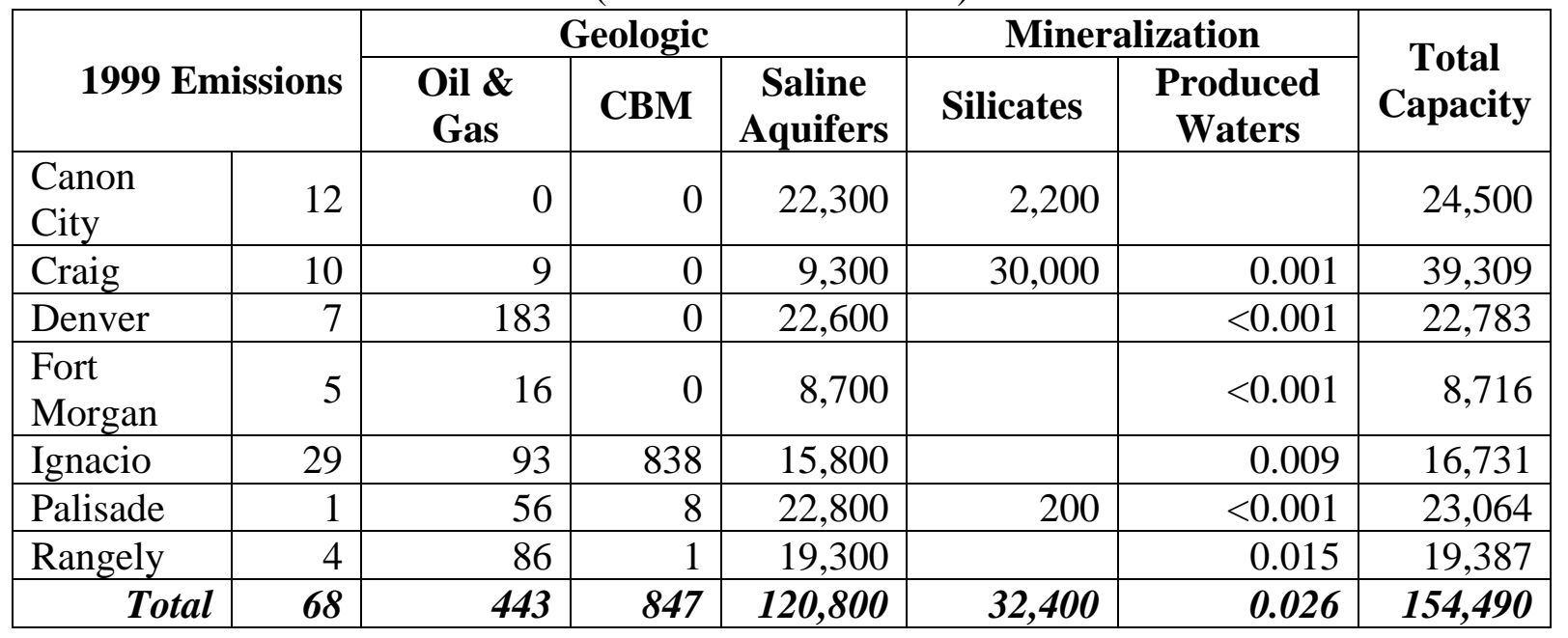

Utilizing both geologic and mineralization options, the preliminary forecast for $\mathrm{CO}_{2}$ sequestration within the seven primary study areas exceeds 150 billion tons. These areas have the potential of providing several hundred years of carbon storage based on 1999 emission levels. The Denver study area provides the greatest potential for oil, gas, and saline aquifer storage. The Ignacio study area provides the greatest known potential for carbon storage in coalbed methane reservoirs. The Craig study area provides the greatest mineralization potential.

There are approximately 1,400 oil and gas fields in Colorado; about 223 of these fields constitute large-volume producers; that is, cumulative production exceeds 1 million bbl and / or 10 bcf of gas. More than half of these large-volume producing fields (122) are located within 30 miles of a large $\mathrm{CO}_{2}$ point source consisting of one or more coal-burning power plants. All of these 122 large-volume fields produce from oil and gas reservoirs that are deep enough to maintain $\mathrm{CO}_{2}$ at supercritical conditions. A minimum level of data has been compiled on all oil and gas fields in Colorado, consisting primarily of location, geologic age, production, discovery date, and depth. Where data are available in the public domain, additional reservoir properties such as porosity, permeability, gas and oil composition and fluid properties have also been compiled, particularly for those reservoirs within the seven primary study areas. Data sources consisted of the Colorado Oil and Gas Conservation Commission, PI/Dwight's, and DOE and state geological publications. The preliminary forecast of $\mathrm{CO}_{2}$ capacity for oil and gas reservoirs in the seven study areas is 443 million tons with more than $80 \%$ of that capacity contained in the Denver, Ignacio, and Rangely study areas (Table 2). This estimate is based on cumulative production through December 2003. This was accomplished by converting all liquid production to thousand cubic feet at surface conditions (Mscf), combining this volume with gas production, and then applying a conversion factor of $17.15 \mathrm{Mscf}$ per ton $\mathrm{CO}_{2}$. This $\mathrm{CO}_{2}$ capacity calculation for Colorado should be considered conservatively low due to the significant underestimation of water production for the state.

Deep unmineable coal for Colorado was defined as coal-bearing formations occurring between 2,000 and 7,500 feet of depth. Coal parameters such as rank, gas content, ash and moisture content were compiled from Bureau of Mines data, Gas Research Institute reports, and state geological publications. The vast majority of coals in the state are bituminous in rank, 
which makes them suitable for enhanced coalbed methane recovery and carbon sequestration. The preliminary forecast of $\mathrm{CO}_{2}$ capacity for coalbed methane reservoirs in the seven study areas is 847 million tons with nearly all of that capacity associated with the Fruitland coal play in the Ignacio study area (Table 2). This estimate of capacity was made by applying a ratio of four $\mathrm{CO}_{2}$ molecules to replace production of one methane molecule. In reality, the process is far more complicated than this and requires a reservoir simulator to calculate accurately. As with the forecast for oil and gas reservoirs, this $\mathrm{CO}_{2}$ capacity calculation for Colorado should be considered conservatively low due to the absence of significant coalbed methane production in emerging basins such as the Sand Wash Basin in the Craig study area.

The criteria used to select formations suitable for $\mathrm{CO}_{2}$ sequestration in deep saline aquifers included lithology consisting primarily of sandstone or other rock with sufficient porosity and permeability, depth exceeding 800 meters (to maintain supercritical conditions), salinity exceeding 10,000 ppm to minimize the probability that the formation would be developed for potable water in the future, and the presence of an overlying formation that would function as a top seal to prevent vertical migration of injected $\mathrm{CO}_{2}$. With only a couple of exceptions, all of the 18 formations evaluated for this project had some historic oil or gas production. This implies the existence of a long-term structural or stratigraphic trapping mechanism that will decrease the probability of upward migration of sequestered $\mathrm{CO}_{2}$. Data sources consisted of TBEG, COGCC, CDWR, RMAG publications, USGS, state geological publications, and numerous others, including an abundance of information on the internet. The amount of carbon that a given formation can sequester was calculated using the sequestration calculator found on the Midcontinent Interactive Digital Carbon Atlas and Relational dataBase (MIDCARB) website. The calculation is based on empirical data for solution of $\mathrm{CO}_{2}$ in water under various temperature, pressure and salinity conditions. The part of the calculator used for this study is based on the assumption of $\mathrm{CO}_{2}$ dissolution only, with no consideration given to the volume of displacement by $\mathrm{CO}_{2}$ versus dissolution. The preliminary forecast of $\mathrm{CO}_{2}$ capacity for saline aquifers in the seven study areas is 120,800 million tons with more than $70 \%$ of that capacity contained in the Canon City, Denver, Palisade, and Rangely study areas (Table 2). This number represents only the capacity within a 30 -mile radius of the primary $\mathrm{CO}_{2}$ sources. The actual capacity of the entire formations will be much greater.

All gathered data has been compiled in a combination of Microsoft Excel spreadsheets and Access databases. A complete set of ESRI ArcMap Shapefiles with attribute tables and metadata have also been assembled. All digital data will be provided to Utah's Automated Geographic Reference Center for use in further analysis.

New Mexico: Using cumulative production cutoffs of one million barrels of oil (1 mmbbl) and/or ten billion cubic feet of gas (10 BCF), 507 Permian Basin (PB) Pools (reservoirs) and 80 San Juan Basin (SJB) Pools were identified as potential $\mathrm{CO}_{2}$ sinks. Each of these pools was assigned a unique number, usually the state mandated, Oil Conservation Division (OCD) number, and entered into the modified GASIS database. In addition, the database also contains detailed information on four natural $\mathrm{CO}_{2}$ pools and the West Pearl Queen Pool (PB), which was chosen as the field demonstration site for $\mathrm{CO}_{2}$ sequestration in NM. The SJB list contains seven pools that did not quite meet the production criteria, but were in close proximity to the two power plants and were similar geologically to the top choices. The names and exact locations of all the pools have been entered into a GIS database so that their spatial relationships to each other, the power plants, population centers, geographic grids, etc. can be portrayed in Arcview. 
The following major sources of data were used to obtain the detailed information for the GASIS Database:

- The Roswell Geological Society Oil and Gas Fields of Southeastern New Mexico (1956, 1960, 1967, 1977, 1988, 1999).

- The Four Corners Geological Society Oil and Gas Fields of the Four Corners Area (1978, 1983).

- The Atlas of Major Rocky Mountain Gas Reservoirs (1993).

- State of New Mexico, Energy, Minerals, and Natural Resources Department, Oil Conservation Division Orders.

- The detailed well and pool data housed at the New Mexico Bureau of Geology's Petroleum Records Section.

The search engine in the GASIS (Access) Database was modified to find pools that met or exceeded ten key criteria; e.g. specified distance from power plants, thickness, porosity, cumulative production, and depth. From the list of 14 pools that were within 50 miles of the power plants, at least $3000 \mathrm{ft}$ deep, and had produced at least 1.5 million bbl of oil and/or 10 BCF gas, Barker Dome Paradox Pool and Ute Dome Paradox Pool were selected as the top two choices for the test case analysis for $\mathrm{CO}_{2}$ sequestration. Barker Dome is located in both New Mexico and Colorado and thus involves two state-regulatory agencies. Detailed summary of these two pools is provided below.

1. Barker Dome Paradox Pool (San Juan Basin/Four Corners Platform): Advantages:

- Algal limestone reservoir with effective clay seal (isolated geographically).

- The reservoir is a folded reef (isolated structurally).

- Cumulative production of more than 180,000 bo, 1,000,000 b water, and 130 bcfg.

- Reservoir at a depth of more than 8,500 ft.

- Discovery well is within a 20 mile radius NE of the power plants.

- Average reservoir thickness is $100 \mathrm{ft}$.

- The Barker Creek Reservoir ("Sour Zone") contains 13.5\% $\mathrm{CO}_{2}$. The "Sweet Zone" reservoirs, which are 200-500 ft above and whose production is reported separately, contain only traces of $\mathrm{CO}_{2}$. This Barker Creek Reservoir does NOT leak CO2.

- The Dakota pool (24 bcfg) is 5,000 feet above. If $\mathrm{CO}_{2}$ were to leak past the Pennsylvanian reservoirs, it could be trapped here.

- No nearby outcrop of Paradox Formation. (No potential surface leakage.)

- No nearby population centers.

- Located in San Juan County, NM and La Plata County, CO.

Issue(s) needing further evaluation:

- Located on Southern Ute Indian Reservation.

- Two smaller, but similar Pennsylvanian pools (Table Mesa Penn [7.1 bcfg, 174,000 bo, w/in $20 \mathrm{mi} \mathrm{SW}$ ] and Hogback Penn [0.67 bcfg, 503,000 bo, w/in $10 \mathrm{mi} \mathrm{SW]}$ that almost made the production cutoffs are also potential candidates.

- The Dakota Pool above is near the depth cut-off for supercritical $\mathrm{CO}_{2}$ and could possibility provide additional $\mathrm{CO}_{2}$ storage capacity.

\section{Ute Dome Paradox Pool (San Juan Basin/Four Corners Platform):}

Advantages: 
- Algal limestone reservoir with effective seal.

- The reservoir is an anticline with few faults.

- Cumulative production of more than 90,000 bo, 85,000 bw, and 110 bcfg.

- Reservoir at a depth of more than 8,600 ft.

- Discovery well is within a 20 mile radius NE of the power plants.

- Average reservoir thickness is $116 \mathrm{ft}$.

- The Dakota pool (26 bcfg) is 6,000 feet above, where any leaked $\mathrm{CO}_{2}$ could be trapped.

- No nearby outcrop of Paradox Formation.

- No nearby towns

Issue(s) needing further evaluation:

- Located on Southern Ute Indian Reservation.

- Located a few miles southeast of Barker Dome; it could be used in tandem with Barker Dome, thus saving pipeline costs..

In addition to these two sites seven other pools were also chosen for further analysis. These pools are at varying distances from the power plants and produce from different depths (from four reservoirs) to allow for variability in the test case analyses (Table 3).

Table 3. Pools in New Mexico

\begin{tabular}{|c|c|c|c|c|c|}
\hline Field Name & Reservoir Name & $\begin{array}{l}\text { Cum Gas } \\
\text { (BCF) }\end{array}$ & $\begin{array}{l}\text { Cum Oil } \\
\text { (mmbo) }\end{array}$ & $\begin{array}{c}\text { Cum Water } \\
\text { (mmbw) }\end{array}$ & $\begin{array}{l}\text { Producing } \\
\text { Wells }\end{array}$ \\
\hline ALBINO & $\begin{array}{l}\text { PICTURED CLIFFS } \\
\text { (GAS) }\end{array}$ & 12.3 & 0.01 & 0.57 & 13 \\
\hline $\begin{array}{l}\text { ANGELS } \\
\text { PEAK } \\
\text { BARKER }\end{array}$ & $\begin{array}{l}\text { GALLUP } \\
\text { (ASSOCIATED) }\end{array}$ & 82.1 & 1.04 & 0.07 & 45 \\
\hline DOME & $\begin{array}{l}\text { PARADOX POOL } \\
\text { LOWER GALLUP }\end{array}$ & 135.9 & 0.18 & 1.29 & 7 \\
\hline BISTI & (OIL) & 77.3 & 40.69 & 46.18 & 179 \\
\hline CHA CHA & $\begin{array}{l}\text { GALLUP } \\
\text { GALLUP }\end{array}$ & 19.0 & 10.44 & 14.63 & 20 \\
\hline $\begin{array}{l}\text { GALLEGOS } \\
\text { TABLE }\end{array}$ & $\begin{array}{l}\text { (ASSOCIATED) } \\
\text { PENN C }\end{array}$ & 41.9 & 2.38 & 0.19 & 42 \\
\hline $\begin{array}{l}\text { MESA } \\
\text { TOCITO }\end{array}$ & $\begin{array}{l}\text { (ABANDONED)* } \\
\text { PENNSYLVANIAN }\end{array}$ & 7.1 & 0.17 & & 0 \\
\hline DOME & D (ASSOCIATED) & 28.8 & 13.26 & 17.81 & 20 \\
\hline UTE DOME & PARADOX (GAS) & 111.6 & 0.09 & 0.09 & 12 \\
\hline
\end{tabular}


seal integrity. The SJB is one of the top ranked basins for $\mathrm{CO}_{2}$ coaled sequestration because it has: 1) advantageous geology; 2) abundant anthropogenic $\mathrm{CO}_{2}$; 3) low capital and operating costs; 4) well developed natural gas pipeline system; and 4) companies with CBM expertise. Selection of a potential coal bed methane $\mathrm{CO}_{2}$ sequestration sites in SJB is difficult and will require more detailed reservoir studies than are available in the literature because: 1) the coal seams are discontinuous; 2) the major coal-bearing formation in the San Juan Basin is generally too shallow to keep the $\mathrm{CO}_{2}$ in super critical state; and 3) all coalbed methane production from the Fruitland Formation in the SJB is now lumped together, making it difficult to know how much methane has been produced from a single reservoir Publicly available information on deep saline aquifers in New Mexico is fragmented and scattered in the geologic and hydrologic literature. The Texas Bureau of Economic Geology (BEG) has compiled data on the Morrison Formation of the San Juan Basin in its study of "Optimal Geological Environments for $\mathrm{CO}_{2}$ Disposal in Brine Formations (Saline Aquifers) in the United States.” They noted (p.32) that “... the same attributes that make saline water-bearing formations desirable as disposal sites (isolation, low potential for economic use, and few well penetrations) are those for which we have little direct information.”

Oklahoma: There are presently more than 2200 oil and gas pools in the Oklahoma data collection. Of this number, 612 of the pools listed have cumulative recoveries of greater than 1 $\mathrm{MMBO}$ and 745 of the pools have cumulative gas recoveries greater than 10 BSCF (with some duplication). There are 26 Oklahoma reservoirs that have produced in excess of $100 \mathrm{MMBO}$ and $160+$ fields that have produced in excess of $10 \mathrm{MMBO}$. There are also 11 major gas fields (> 1 ccf of gas produced) and more than 90 Tcf has been reported as sold within the State. Estimates of remaining oil in place from pools in the State are between 42 and 93 BBO. Some 40 inactive and/or abandoned fields that have produced more than $1 \mathrm{MMBO}$ have been identified. The majority of the large gas fields are still producing.

Since most of the large fields in Oklahoma were discovered and exploited prior to 1955, there is very little electronic data available on the field-level. Thus the primary sources for data have been the original DOE database systems GASIS (725 pools) and TORIS (65 pools) with the remainder coming from a library search of reference and geological textbooks, Oklahoma City Geological Society publications, Oklahoma Geological Survey and United States Geological Survey transactions, circulars and other publications, and University of Oklahoma Master of Science theses and $\mathrm{PhD}$ dissertations.

Future plans for data collection and assimilation include expanding the search to include aquifer and coal-seam information and cleaning the existing oil and gas data, ensuring that the data is of high quality.

Since any number of the large fields in Oklahoma would be strong, candidates for potential $\mathrm{CO}_{2}$ utilization given that the age of the fields would certainly test a variety of the measurement, monitoring and verification options that exist, the Oklahoma Geological Survey (OGS) and the University of Oklahoma Mewbourne School of Petroleum \& Geological Engineering (MPGE) hosted a meeting in Norman, Oklahoma on June 29, 2004, to evaluate interest in the implementation of carbon sequestration in Oklahoma. Attendees included 43 decision-makers or their designees from the top oil and gas producers in the state of Oklahoma (especially with $\mathrm{CO}_{2}$ operations); individuals who had participated in various previous OGS- or MPGE-sponsored events; corporations which are major sources of $\mathrm{C}_{2}$ emissions and/or sources currently capturing $\mathrm{CO}_{2}$; and researchers or entities who have written proposals or conducted research in 
sequestration-related activities who wanted to both learn more about the Partnership program and what it could offer their organizations and the state of Oklahoma, as well as to exchange ideas on how to move forward to a potential pilot project. From this meeting, two potential projects were presented to the attendees and several additional possibilities were discussed as being "interesting".

The first of the projects discussed was an infrastructure expansion project that would extend the current $\mathrm{CO}_{2}$ pipeline system in the State and connect this system to additional anhydrous ammonia and other gas and power plants that exist in Oklahoma and Kansas. The current pipeline system has one portion that comes from an anhydrous ammonia plant in Borger, TX and supplies an enhanced recovery project in the south-central panhandle and another that starts at an anhydrous ammonia plant in Enid, OK that supplies $\mathrm{CO}_{2}$ to several fields in south-central Oklahoma. This last pipeline actually runs through some of the most productive areas in the State. An extension of both of these lines to the north would contact a number of gas and power plants as well as several large fields in Kansas and an extension of the central line to the east would contact the large, relatively shallow fields near Tulsa where poor recovery factors at present could result in a significant economic impact on the State. The operator of the existing pipeline system, Chaparral Energy, presented an outline of their plans to the participants and discussed several possible stages to the expansion.

The second potential project that was discussed was an aquifer sequestration site in northwestern Oklahoma close the town of Freedom, OK. This site is at the northern end of a geologic structure known as the Woodward trench and is a 1-2 mile wide by 70 mile incised valley fill of sand and shale of Pennsylvanian (Morrow) age. The channel is isolated from the surrounding (much tighter) Chester limestone with an approximate depth of 6,700 feet. The Beard Company in Oklahoma City presented this prospect and have proposed that four wells that have been cemented to surface and could likely receive EPA Class I status if tested, be used to inject $\mathrm{CO}_{2}$ into the trench. The wells have good porosity (published reports put the porosity values for the trench at approximately 14\%) and permeability (published values are around 20-40 mD) in the zone of interest and were formerly used to produce iodine. The iodine was extracted from brine that was produced from the wells and then the brine was reinjected into the formation. Rates for both production and injection were in excess of 2000 barrels per day so reasonable rates of CO2 injection should be expected.

Several additional ideas were discussed at the meeting. The status and potential expansion of the project being run by the Kansas Geological Survey and the University of Kansas Tertiary Oil Recovery Project was one such idea. Utilization of captured $\mathrm{CO}_{2}$ from the AES Shady Point power plant which currently separates and captures about 5\% of its effluent stream for sale to Tyson Chicken in Arkansas was also discussed. Coal seams in the eastern part of the State would seem to be the most likely target for sequestration, with some of the prolific oil fields near Tulsa as another possibility. One company discussed the possibility of utilizing the coal seams once the methane that they are producing has been extracted (their belief was that they could extract the methane more efficiently through depletion than they could through ECBM methods).

Utah: During the past year the Utah Geological Survey (UGS) spent considerable time coordinating with the other participating states in the modification of the DOE GASIS database for use by the partnership in characterization of the geologic sinks in the study area. After finalizing the new database in February 2004, the UGS's data collection and updating efforts were begun for the new geologic sinks database. The updating and data collection efforts 
included adding new information to reflect oil and gas development activities for the past 10 years since the GASIS database was compiled including: adding fields, adding new reservoirs to deepened fields, expanding the number of wells and the productive area of fields, updating production data, adding new information not in the original GASIS database on oil and coal properties, and adding other available data. The UGS has completed 99\% of Utah's portion of the database entry for the 68 conventional oil and gas fields studied (94 separate reservoirs, some fields have multiple pay zones), completed 95\% complete of the data entry for the seven CBM fields studied, and data on deep saline aquifers has been compiled by Dr. Jim Evans of Utah State University and will be entered shortly. The UGS also provided the Utah AGRC with GIS shapefiles on the location and size of all the oil and gas fields in Utah as part of publishing an updated map of oil and gas fields of Utah (UGS Map 203DM, by Thomas C. Chidsey, Jr., Sharon Wakefield, Bradley G. Hill, and Michael Hebertson, 1 pl., scale 1:700,000, on CD-ROM, ISBN 1-55791-709-4). These shapefiles were given field ID number attributes so that they could be cross-referenced to the oil and gas fields in the database. The UGS also made a preliminary screening of the conventional oil, gas, and CBM geologic sinks to see which ones would be good candidates for a pilot $\mathrm{CO}_{2}$ sequestration project.

\section{$\mathrm{CO}_{2}$ Mineralization Storage Options for the Southwest Region}

The Southwest Regional Partnership is evaluating the role of $\mathrm{CO}_{2}$ mineralization (the process by which $\mathrm{CO}_{2}$ is bound in a solid) as an integral component of regional $\mathrm{CO}_{2}$ storage options. Three broad roles are being considered. Above-ground mineralization using cations extracted from either from produced waters (e.g., brines) or mined ores (e.g., silicates) offer two potential roles for engineered long-term storage. Although no workable process currently exists for these options, ongoing research in both areas is encouraging and may open an intriguing option in the Southwest's portfolio. Below-ground mineralization via in situ brine- $\mathrm{CO}_{2}$-rock interactions can also play a role in Southwest's portfolio. Although complete mineralization of a $\mathrm{CO}_{2}$ plume may be restricted to specialized geologic units, partial mineralization could play a key role in determining the long-term fate of $\mathrm{CO}_{2}$ by altering and (potentially) sealing flow pathways. These phenomena can occur on timescales difficult to characterize completely in the lab, but the Southwest's analogs_-both natural and anthropogenic (e.g., EOR)—provide the opportunity to investigate these processes at times scales ranging from decades to eons.

This subtask involved:

- defining the mineralization options available to the region;

- evaluating the state of the research for these options;

- identifying the distribution, size, and nature of potential resources in the area that could be used for mineralization should mineralization technology reach an implementation stage.

The mineralization options being investigated in the Southwest region fall into four categories:

- Brine mineralization

- Silicate mineralization

- In Situ mineralization

- Trona mineralization 


\section{Brine Mineralization}

Brine mineralization is being evaluated as an option by the team in the context of brine extraction (possibly as produced waters) and conversion to solid carbonates. The current state of research was assessed in the context of ongoing R\&D primarily at New Mexico Tech by Dr. Gillian Bond and coworkers. Their work has shown that mineralization can occur under appropriate conditions and that the rate of the reaction can be enhanced by the use of enzymes that catalyze the hydration of $\mathrm{CO}_{2}$, which is believed to be the rate-limiting step for this process. Research using the enzyme HCA II with brine simulants has shown that the hydration step can, indeed, be accelerated and that calcium carbonate can be precipitated from both low and high cation concentration solutions. This research has also demonstrated an approach for flowthrough applications as well as their robustness with respect to potential industrial constituents such as $\mathrm{SO}_{\mathrm{x}}, \mathrm{NO}_{\mathrm{x}}$, As, and $\mathrm{Hg}$. An economic route for the enzyme has been identified (bacterial overexpression of HCA II).

Preliminary assessments of brine resources in the Southwest are underway, focusing on brine chemistries and volumes as well as the relationship of brine mineralization to associated processes such as oil production. Ultimately, the economics of brine mineralization may be closely tied to costs associated with oil production and/or the economics of regional water needs. These issues need to be a component of the regional $\mathrm{CO}_{2}$ assessment strategy.

Remaining technical challenges for the brine mineralization work appear to be: (1) determining ultimate mass-balance relationships between brine chemistry and mineralization potential with respect to the formation of carbonic acid, (2) quantification of the mineralization rates as a function of brine chemistry, and (3) engineering issues (such as scaling up of the process; materials handling, etc.).

\section{Silicate Mineralization}

Silicate mineralization is being evaluated as an option by the team in the context of the extraction of bivalent metals (primarily $\mathrm{Mg}^{2+}$ and $\mathrm{Ca}^{2+}$ ) in an industrial process, where silicate ores and waste streams are used as a source for the metals. The current state of research was assessed in the context of ongoing R\&D primarily at Arizona State University (by Mike McKelvy and coworkers), Los Alamos (by Hans Ziock, George Guthrie, and coworkers), and related efforts at a number of other institutions primarily in the U.S. and Norway. This work has shown that mineralization can occur under appropriate conditions but that the rate of the reaction for the pathways investigated to date appears to be too slow for an economically feasible industrial process (except for a few materials such as selected calcium silicates, for which the rates appear reasonable but the resources appear limited). Research is focused on identifying a method for speeding the rate. The release of metal from the silicate is believed to be one of the principal limits to the overall rate, and work on this aspect has focused on (1) mechanical enhancements, (2) thermal enhancements, (3) chemical enhancements (e.g., catalysts), or (4) combinations of these. To date, there is no method that appears to enhance rates sufficiently while maintaining feasibility (i.e., with respect to economics, energy balance, or engineering). However, recent research appears encouraging, particularly with respect to understanding the reaction mechanism at the molecular level and with respect to chemical enhancements.

Preliminary assessments of the silicate resources in the Southwest are underway, focusing on mineable resources with appropriate chemistries and on byproduct streams from other processes (such as fly ash, slag, etc.). 
Remaining technical challenges for silicate mineralization appear to be rates and mechanisms of reaction (as noted above) and engineering issues (such as scaling up of the process; materials handling, etc.).

\section{In Situ Mineralization}

In situ mineralization relates to the ability to mineralize $\mathrm{CO}_{2}$ in the subsurface in association with an injected $\mathrm{CO}_{2}$ plume. The team considered two end-member situations: complete (bulk) mineralization of the $\mathrm{CO}_{2}$ and partial localized mineralization (as it impacts porosity/permeability). In the first category, no specific resources have been identified (e.g., large scale interbedded basalts and sandstones), but this will be re-evaluated in light of the tabulated geologic data. In the second category, this process is being considered in the context of the hydrogeochemistry of geologic storage at a number of institutions and will be addressed by those studies.

Remaining technical issues relate to the rates of mineral dissolution (primarily silicates) and precipitation of carbonates in geologic media. The team did not delve into the state of this research in detail.

\section{Trona Mineralization}

Trona mineralization involves the conversion of a solid sodium carbonate into a bicarbonate liquid or solid. The reaction involves taking trona and reacting it with $\mathrm{CO}_{2}$ according to the reaction:

$$
\mathrm{NaHCO}_{3} \cdot \mathrm{Na}_{2} \mathrm{CO}_{3} \cdot 2 \mathrm{H}_{2} \mathrm{O}+\mathrm{CO}_{2} \rightarrow 3 \mathrm{NaHCO}_{3}+\mathrm{H}_{2} \mathrm{O}
$$

thereby effectively converting the sodium carbonate portion of trona into sodium bicarbonate. Large deposits of trona exist in various parts of the western U.S. (notably in Wyoming) but may also occur elsewhere in the Southwest region. Some preliminary assessments of the method are underway, and, if encouraging, will be followed up with an assessment of regional resources. As an example, the Wyoming deposit alone is estimated to be sufficient to address regional needs for decades.

\section{Summary}

$\mathrm{CO}_{2}$ mineralization is a potential long-term sequestration option in the Southwest portfolio, where terrestrial and geological sequestration are clear options in the near term. Continued laboratory scale research into lowering the cost of $\mathrm{CO}_{2}$ mineralization is essential to explore its long-term potential as a viable alternative, as the optimum terrestrial and (lower cost) geologic sites are utilized fully or as other economic factors (e.g., the value of mineralization byproducts) become significant.

\section{Summary Discussion of Subtask 1.3: Separation and Capture Technologies Employed in the} Southwest Region

The Regional Partnerships for Carbon Sequestration programs funded by DOE are ultimately required to identify the best carbon sequestration options in their respective regions, consisting of a $\mathrm{CO}_{2}$ source, applicable $\mathrm{CO}_{2}$ capture technology, transportation logistics (if applicable) and destination formation for non-terrestial sequestration approaches. In most cases the carbon capture step is the most costly, and selecting the appropriate least-cost options will be of 
particular importance. The Gas Technology Institute (GTI) was selected to provide advice and consultation on capture technologies for the Southwest Partnership.

This section summarizes commercial technology and costs applicable to point sources in the southwest region, which are mainly coal-fired power plants. Other sources include natural gas processing plants, refineries, ethanol plants, and cement plants. Research in progress to develop new technologies for carbon dioxide capture will also be briefly summarized. This information will assist in identifying candidate projects for Phase II.

\section{Scope of Work}

The objective of this subtask is to delineate technologies applicable to capturing carbon dioxide from point sources and to provide estimates from various sources of the specific costs of such technologies. Research and development on new technologies will be reviewed and a listing of those that appear promising and are sufficiently in the development cycle will be presented.

\section{Background Information for $\mathrm{CO}_{2}$ Capture}

The capture of $\mathrm{CO}_{2}$ must occur before $\mathrm{CO}_{2}$ can be sequestered. Several excellent reviews of the subject have been published (see particularly Curt M. White et al., 2003 Critical Review: Separation and Capture of $\mathrm{CO}_{2}$ from Large Stationary Sources and Sequestration in Geological Formations_-Coalbeds and Saline Aquifers, presented at A\&WMA's 96th Annual Conference \& Exhibition in San Diego, CA, June 2004.)

The approach to capture has been delineated into three major approaches: postcombustion, oxycombustion, and precombustion (or decarbonization). Figure 4 (courtesy Carbon Capture Project) illustrates these approaches in a simplistic way:

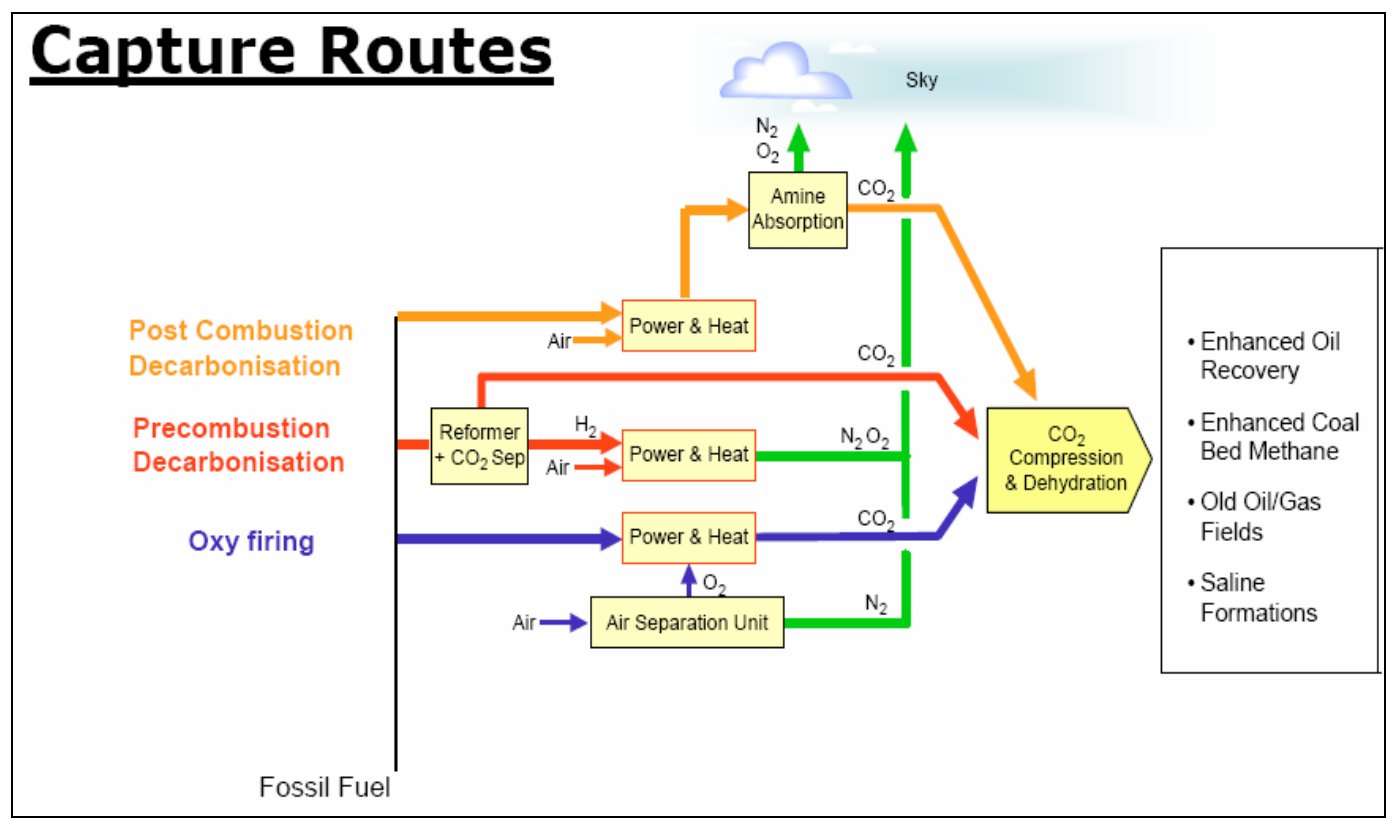

Figure 4. $\mathrm{CO}_{2}$ capture approaches. 


\section{Postcombustion Decarbonization}

Postcombustion approaches refer to the application of various technologies to the removal of carbon dioxide from the flue gases resulting from combustion. As the following sections will discuss in more detail, amine (a weak base) absorption processes are commercially available to effect this removal. Drawbacks are residual oxygen in the flue gas that degrades the amine, low concentration of oxygen, low working pressures resulting in large equipment, and low concentration of $\mathrm{CO}_{2}$ to be removed ( $\left.<15 \%\right)$, also resulting in large equipment sizes and high solvent circulation rates. This approach is generally the only one available to remove $\mathrm{CO}_{2}$ from already existing power plants and other large "point sources". Both Fluor and ABB offer commercial embodiments of this technology based on the amine monoethanolamine (MEA). Mitsubishi offers a newer solvent, KS-1, but the basic process is the same. Relatively limited experience exists with coal fired flue gases in pulverized combustion (PC) power stations.

\section{Precombustion Decarbonization}

Precombustion decarbonization refers to various processes that convert the fuel at high pressure into a synthesis gas, mainly $\mathrm{CO}, \mathrm{CO}_{2}$ and $\mathrm{H}_{2}$. The non-hydrogen species can be more readily and inexpensively removed at the high pressure, high concentration, oxygen-free conditions that result. Typically this approach is coal gasification followed by $\mathrm{CO}_{2}$ removal using a physical solvent and possibly chemical reactors conducting water gas shift to produce additional hydrogen from the $\mathrm{H}_{2} \mathrm{O}$ and $\mathrm{CO}$ in the syngas. Reforming is another prominent example of precombustion decarbonization, where natural gas and certain liquid hydrocarbon fuels (e.g., naphtha) are heated over a catalyst at moderate pressures of several hundred pounds. Reforming is currently widely employed to make synthesis gas for fertilizer manufacture or hydrogen for chemical and refinery operations. The integrated gasification combined cycle (IGCC) is an advanced approach along these lines to produce electricity at large central stations, replacing the conventional approach of PC-fired boilers. The Electric Power Research Institute (EPRI) was instrumental in developing this technology by funding the first commercial demonstration plant, Cool Water, in California, a few decades ago. Seven early adopter plants of this type have been built worldwide but further adoption has been hampered by a perception of risk unacceptable to the utility industry and, in the absence of a current requirement to remove $\mathrm{CO}_{2}$ and other trace substances, higher costs. American Electric Power (AEP) has nonetheless announced it will build an IGCC plant in the near future. A photograph of a Selexol (dimethylether of polyethylene glycol) installation at a new IGCC plant in Italy is shown in Figure 5: 


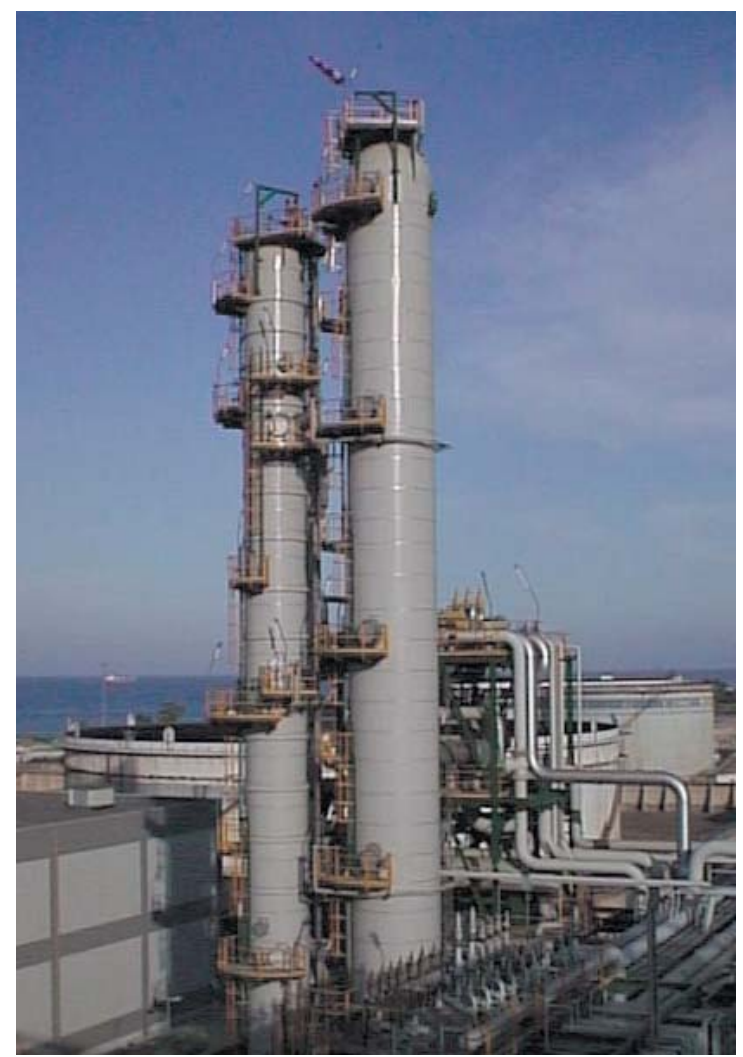

Figure 5. Selexol unit at Sarlux plant, Sardinia.

Removal of naturally occurring $\mathrm{CO}_{2}$ from natural gas in the course of preparing natural gas for pipeline transport is another example of precombustion decarbonization, although the carbon inherent in the fuel molecular structure is not affected. Ultimately, an end user fuel of pure hydrogen could be produced. The product of hydrogen combustion is water alone. Provided that $\mathrm{CO}_{2}$ capture and sequestration were carried out at the hydrogen production plant, no net carbon emissions would occur from the combustion of fuels processed in this manner.

\section{Oxycombustion}

The third major approach is oxyfiring or oxycombustion. Since all fuels are hydrocarbons, the products of complete combustion are $\mathrm{H}_{2} \mathrm{O}$ and $\mathrm{CO}_{2}$. If oxygen is used instead of air in the combustion process, then no nitrogen $\left(\mathrm{N}_{2}\right)$ will be present in the combustion offgas or flue gas, which will increase the concentration of $\mathrm{CO}_{2}$ in the flue gas and simplify and make less expensive the process to remove or capture $\mathrm{CO}_{2}$ from the flue gas. In order to avoid excessive temperatures, which will occur in the complete combustion of a fuel in oxygen, the recycle of cooled flue gas or injection of water to the inlet of the system is required. This technology in undergoing trials in California conducted by Clean Energy Systems at the nominal 5 Mwe scale.

\section{MEA for $\mathrm{CO}_{2}$ Capture from Postcombustion}

Since the major sources of $\mathrm{CO}_{2}$ in the southwest region are coal-fired power plants, any approach to lowering emissions significantly must ultimately deal with these sources. At present the only technology near enough to commercialization is the MEA-based solvent capture technology. Mitsubishi offers an advanced solvent, KS-1, that has a number of advantages over MEA, but this is still in an early commercialization stage. Fluor and ABB both market a 
technology based on MEA. Fluor has the larger installed capacity of the two. Fluor refers to its process as the Econamine FG process, which was developed by DOW and was previously available as the GAS/SPEC FT-1 process. Sixteen commercial plants were built, of which seven are still operating. None of the large plants are operating on coal-fired systems, but several pilot units were tested with coal. Applications of this process to cement plants should be straightforward.

The process flow diagram for this process is shown in Figure 6.

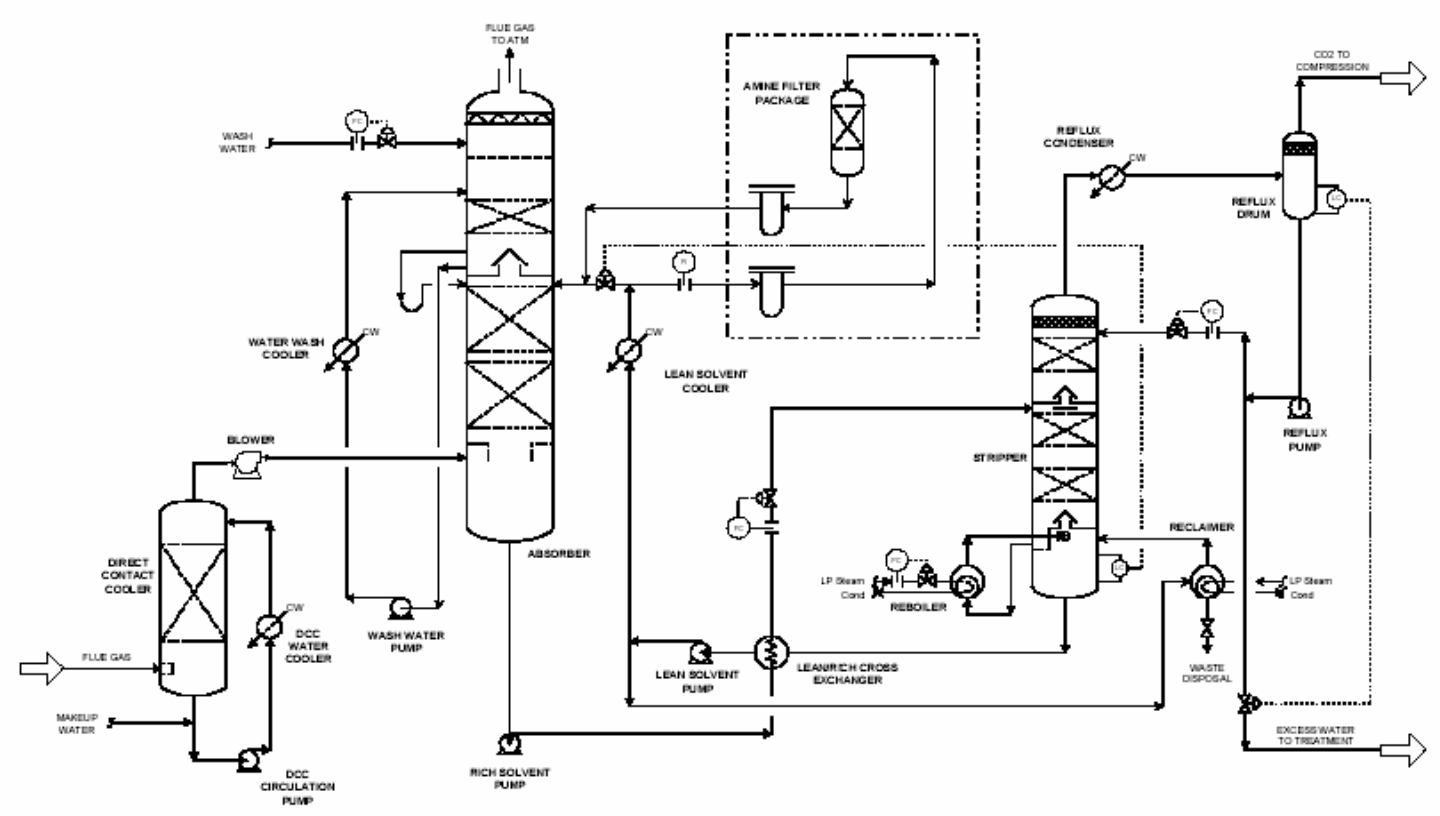

Figure 6. Process flow diagram for the Econamine FG process.

MEA (a solution of 30\% MEA in water) is circulated to the top of the absorber tower where it contacts upflowing flue gas. This flue gas needs to have been cooled to $50^{\circ} \mathrm{C}$ or thereabouts, so in plants without wet FGD units a direct contact cooler will need to be added. A blower is also required to provide the "head" or to overcome the pressure drop that flowing through the absorber tower entails. It reacts with the $\mathrm{CO}_{2}$, which is then carried out of the absorber to a regenerator or stripper. Steam is used to heat the solution, which boils off some of the solution water and "strips" out the $\mathrm{CO}_{2}$ that is then captured, polished, dried and compressed, usually to 2000 psi, for transport. The stripped or lean MEA solution is then pumped back to the absorber for reuse. The process needs steam for the stripping operations, which comes from steam that would otherwise be available in the power plant steam circuit, so there is a "parasitic" power loss. The compressor, blower and solvent circulation pumps also induce parasitic power losses. The total loss of power due to addition of $\mathrm{CO}_{2}$ capture is on the order of $20 \%$.

Drawbacks of this process are high corrosion potential, large MEA losses due to vaporization and degradation, inefficiency, and parasitic power loss.

\section{Estimation of Costs of $\mathrm{CO}_{2}$ Capture}

$\mathrm{CO}_{2}$ capture from large stationary sources has been very sparsely applied and usually occurs in unique situations, for example where there was a particularly robust market for the $\mathrm{CO}_{2}$, such 
as for food grade use, or for EOR in a particularly amenable reservoir. Since capture from electric power stations will be the largest source in most regions we need mainly to be concerned with those costs, which include the costs from near-term power generation technology such as IGCC and possibly from natural gas-fired turbine plants. Costs for such applications can be presently estimated with accuracy probably on the order of $\pm 25 \%$ and no better, and not considering site specifics, which will further broaden the range of estimation accuracy. With the estimation of the costs of $\mathrm{CO}_{2}$ capture and related metrics (see below) for hypothetical processes and processes in early stages, $R \& D$ cannot be done within a range of even $200 \%$. Rand Corporation studied the accuracy of cost estimation of pioneer plants in DOE-funded studies in the 1980s (E.W. Merrow, K.E. Phillips, and C.W. Myers, Understanding Cost Growth and Performance Shortfalls in Pioneer Process Plants (Santa Monica, CA: The RAND Corporation, 1981). Even with technology that is proven and well understood, cost estimates can differ widely based on assumptions of fuel costs, inflation, financing costs, capacity factors, reliability, sparing philosophy, location, site specifics, design philosophy, tax basis, depreciation approach, tax credits and other factors.

In order to bring some sense of order to this a transparent, common basis needs to be established, setting down the assumptions and values of as many parameters as possible. The DOE's National Energy Technology Laboratory (NETL), recognizing this, commissioned the Carnegie Mellon University Center for Energy and Environmental Studies to produce computer software to produce consistent estimates for major power generation approaches with a variety of fuels (natural gas, various coals). Using this program, apple-to-apple comparisons can be made and the necessary comparison metrics for different processes, such as cost of $\mathrm{CO}_{2}$ avoidance (see below) can be generated relatively easily. The Integrated Environmental Control Model (IECM) is publicly available from the CMU Center for Energy and Environmental Studies website at http://www.iecm-online.com/cees_download.htm and is currently in version 4.0.4.1, released in September 2004. The program is not complete; for example, at present the only IGCC scheme is Texaco cold quench, but despite these limitations, representative costs can currently be generated. The GTI has developed similar information for the cost of $\mathrm{CO}_{2}$ removal from natural gas using various processes and at various plant capacities.

\section{Metrics for Evaluation of $\mathrm{CO}_{2}$ Capture}

Important metrics for evaluation of $\mathrm{CO}_{2}$ capture are the "cost of $\mathrm{CO}_{2}$ removal" and the "cost of $\mathrm{CO}_{2}$ avoidance". The former metric is simply the cost of removal of $\mathrm{CO}_{2}$ per unit mass removed. Since efficiency penalties are associated with removing $\mathrm{CO}_{2}$, the net power from any plant fitted with $\mathrm{CO}_{2}$ capture will be lowered, so the cost per net kWh delivered will be higher than the cost of $\mathrm{CO}_{2}$ removal. Thus, additional investment may be required to bring the plant back up to the rated capacity or alternatively, add incremental power by some other acceptable approach without adding to the $\mathrm{CO}_{2}$ emissions. The cost of $\mathrm{CO}_{2}$ avoidance can also be interpreted as the value of the carbon tax (fixed and proportional to $\mathrm{C}$ emissions) at which the "power plant" is indifferent, at a fixed level of $\mathrm{CO}_{2}$ capture, to paying the carbon tax or the cost of $\mathrm{CO}_{2}$ mitigation. The plant would therefore prefer the $\mathrm{CO}_{2}$ mitigation costs at any higher level of carbon taxes.

Other metrics are the cost of electricity (COE) with and w/o carbon capture and the total plant annualized investment. 
Costs for $\mathrm{CO}_{2}$ Capture from Power Plants

Results from applying the IECM model (see above) to a number of scenarios were presented by Rubin at the Third International Conference on Carbon Sequestration held in May 2004 in Alexandria, VA USA.

The following slides excerpted from his paper "Comparative Assessments of PC, NGCC, and IGCC Power Plants with and without $\mathrm{CO}_{2}$ Capture and Storage” are significant.

The comparison is based on $2 \% \mathrm{~S}$ bituminous coal and assumes a capacity factor of $75 \%$ for all of the plants. PC plants are supercritical (but not ultra supercritical) design and the IGCC is based on Texaco cold quench and the Selexol process for $\mathrm{CO}_{2}$ removal. The natural gas combined cycle (NGCC) uses two GE frame 7 turbines. All reference power plants are 560 MW. Since current natural gas prices are so high, the COE from NGCC is also high and actual capacity factors for NGCC plants has been below 35\% in the past year or two. Therefore the calculations and charts are unrealistic for current natural gas prices. NGCC would not be the preferred option for least-cost electricity and actual reductions of $\mathrm{CO}_{2}$ emissions would not be realized at the low capacity factors.

The first slide (shown in Figure 7) plots $\mathrm{CO}_{2}$ emission rates as $\mathrm{kg} / \mathrm{MWh}$ for the three plant types. As can be easily seen, PC and IGCC have similar emission rates, mainly because of using the same fuel, coal. The NGCC plant has an emission rate less than half of the coal-fired units. The values for emission rates are of course less when capture is added at the nominal $90 \%$ capture level but the advantage of NGCC at less than half the emission rate for the coal-fired units is maintained.

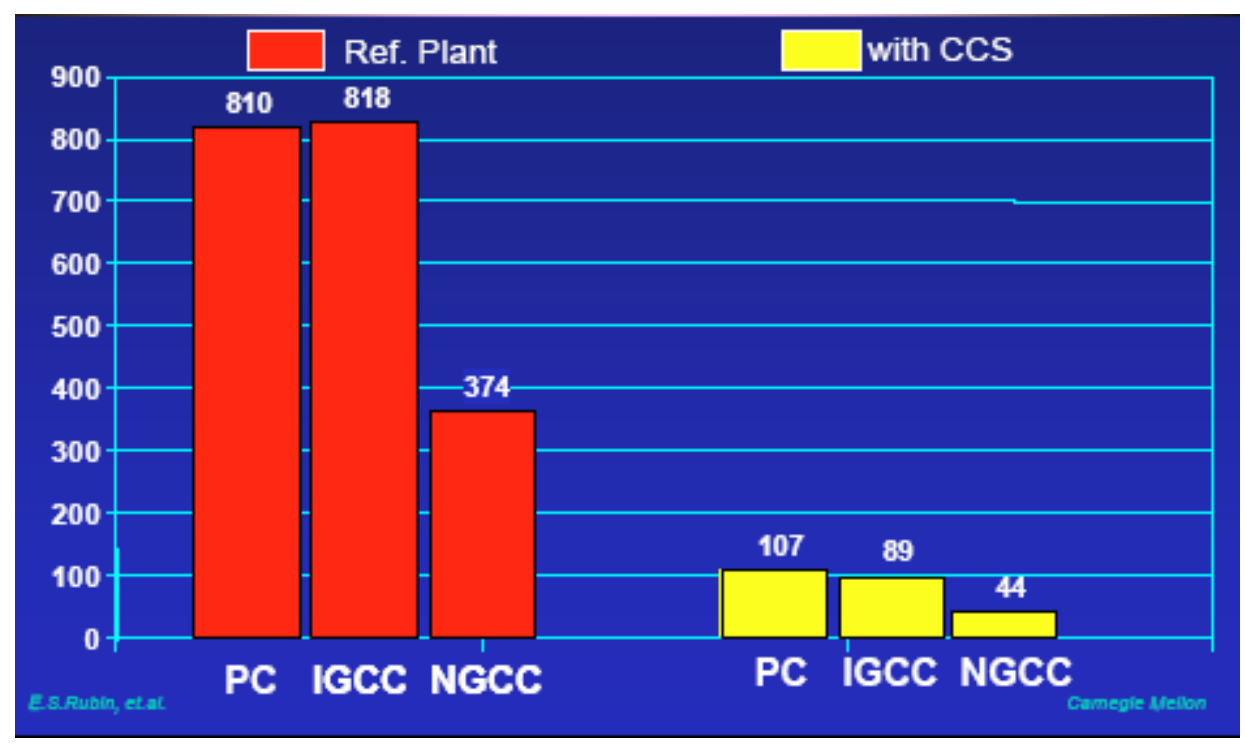

Figure 7. $\mathrm{CO}_{2}$ emission rates (kg/MWh).

The second chart (Figure 8) illustrates the cost of electricity from the three power plant types as well as the respective contributions of the reference plant, capture and transport+storage. We see that the differences in the three plant types is not pronounced when there is no $\mathrm{CO}_{2}$ capture. 
IGCC is slightly more expensive, but by less than $10 \%$ of the COE for the PC plant and less than $15 \%$ of the COE of the NGCC plant. The COE with capture is significantly higher than w/o capture, more than 50\% higher for the PC plant and if transportation and storage is taken into account, $75 \%$ higher. We see that the increase due to capture and due to capture plus storage for the IGCC plant is much less and in fact the COE of the IGCC plant with capture and storage is less than the PC plant with capture and storage and is therefore preferred. NGCC is still the preferred option on the $\mathrm{COE}$ metric. If EOR utilization of the $\mathrm{CO}_{2}$ is a possibility, all of the COEs are reduced but the IGCC produces more $\mathrm{CO}_{2}$ than the NGCC and receives a larger offsetting credit, with the result that it now becomes the preferred option. The cost of $\mathrm{CO}_{2}$ capture in this case for IGCC represents only a 10\% increase over the cost without capture.

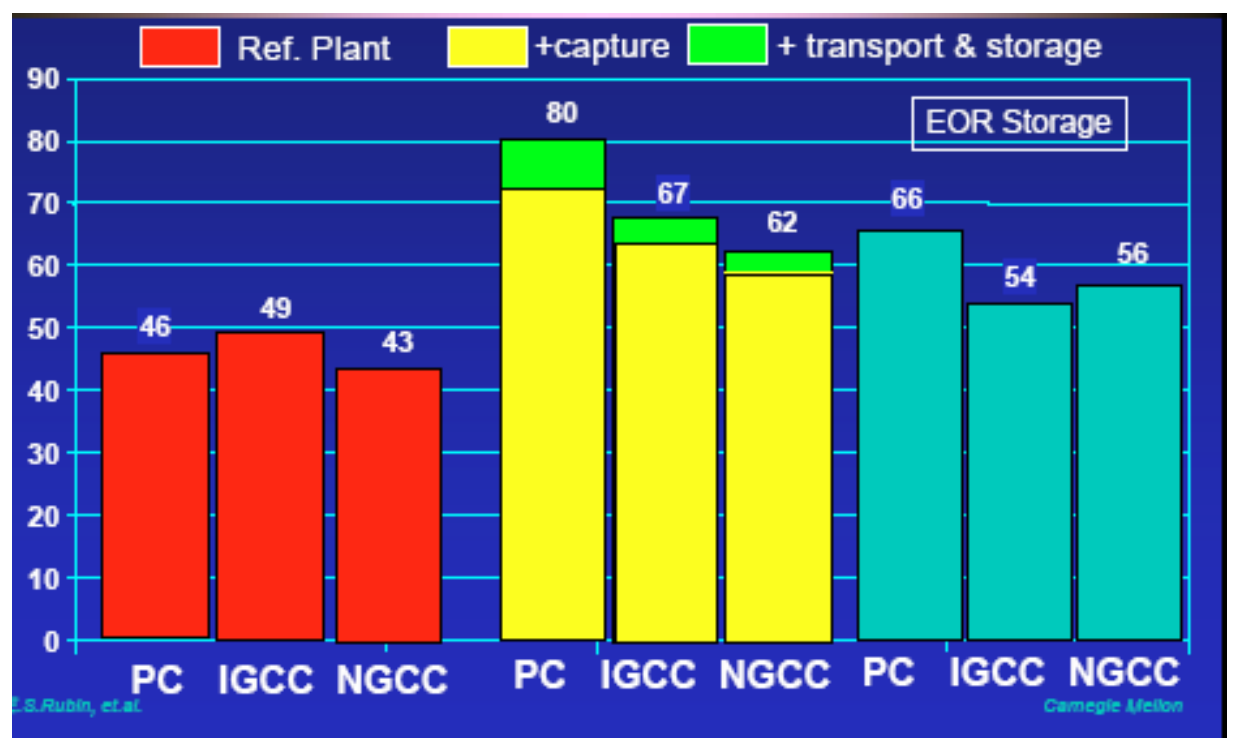

Figure 8. Cost of electricity, COE (levelized \$/MWh).

The avoided cost of $\mathrm{CO}_{2}$ for these cases is shown in Figure 9. For the prevalent PC-fired plants we are looking at $\$ 50$ per ton, nominally. The avoided cost for IGCC plants is approximately $50 \%$ of that for PC plants. NGCC plants have the highest avoided cost. The absolute values of these costs are reduced significantly for the EOR case, but the trends remain and IGCC is still the lowest cost option in this instance. 


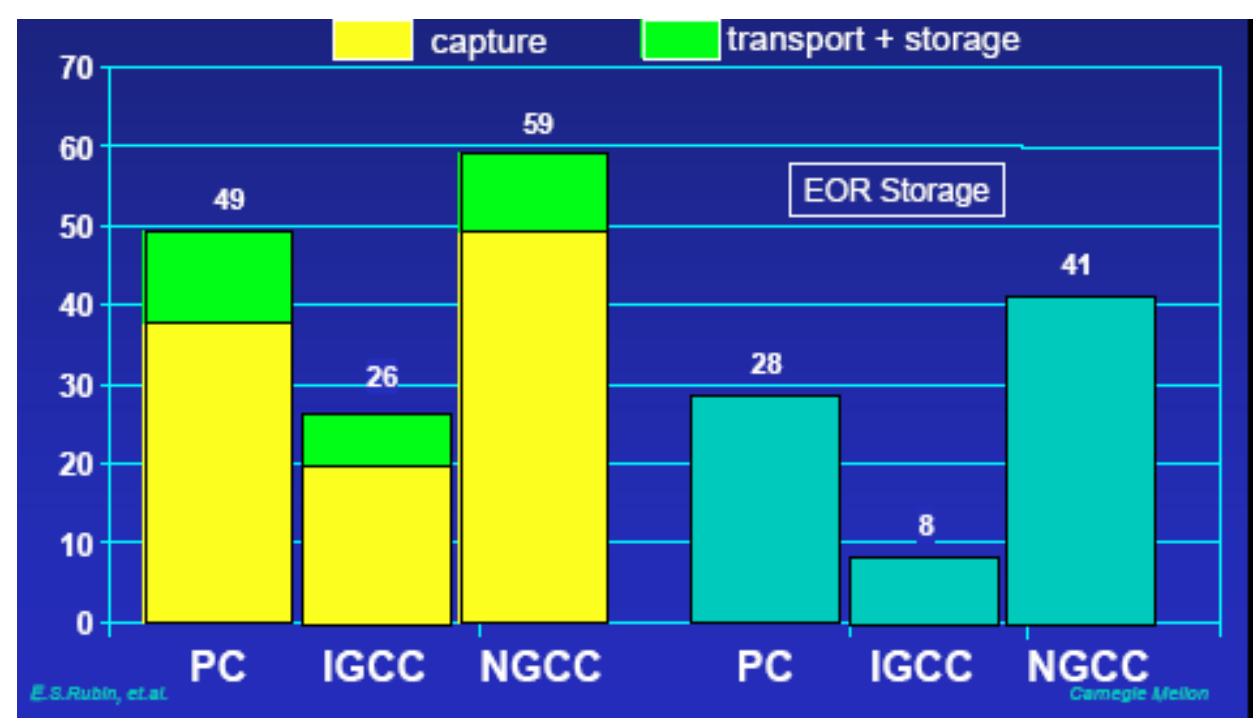

Figure 9. Cost of $\mathrm{CO}_{2}$ avoided (\$/tonne $\left.\mathrm{CO}_{2}\right)$.

It should be recognized that these charts are merely an example and depending on assumptions taken, particularly for fuel costs, we can get different absolute values and draw different conclusions. For this set of assumptions, we can fairly well conclude that IGCC is a preferred option provided the relatively minor increase in electricity cost (COE) over the cost of electricity from NGCC would be acceptable to PUCs and the public in exchange for the societal benefits of reduced $\mathrm{CO}_{2}$ emissions. Barring any legislation or other requirement to capture $\mathrm{CO}_{2}$, it should be clear that capturing $\mathrm{CO}_{2}$ is still an expensive proposition with high costs to the economy and society and results in $40 \%$ more expensive electricity.

This confirms the need to develop advanced technologies to lower the incremental cost of $\mathrm{CO}_{2}$ capture. The approaches currently being pursued worldwide are listed in the next section.

\section{Ongoing Research}

DOE has an aggressive $R \& D$ Program with the objective of reducing the costs of $\mathrm{CO}_{2}$ capture. The IEA Greenhouse Gas Programme has developed a website of Carbon Capture and Sequestration Projects (http://script3.ftech.net/ ieagreen/co2sequestration.htm). The Carbon Capture R\&D listing from their database as of 10/30/04 is shown in Figure 10 (links in the title column are to more detailed information) and includes many of the DOE-funded projects: 


\begin{tabular}{|c|c|c|}
\hline Project Title & Project Overview & Location \\
\hline $\begin{array}{l}\text { The Capture and } \\
\text { Storage of Carbon } \\
\text { Emissions }\end{array}$ & $\begin{array}{l}\text { The project is examining } \\
\text { improvements to the chemical } \\
\text { absorption process (using a variety of } \\
\text { solvents) as well as developing new } \\
\text { technology and carrying out } \\
\text { technology screening studies }\end{array}$ & $\begin{array}{l}\text { Boundary Dam Power Plant } \\
\text { University of Regina }\end{array}$ \\
\hline $\begin{array}{l}\text { CO2 Capture Project } \\
(\mathrm{CCP})\end{array}$ & $\begin{array}{l}\text { The project is a joint initiative } \\
\text { carrying out a development } \\
\text { programme leading to the reduction in } \\
\text { the cost of } \mathrm{CO}_{2} \text { capture from } \\
\text { combustion sources, followed by its } \\
\text { safe, economical underground storage }\end{array}$ & Various Locations \\
\hline NorCap Project & $\begin{array}{l}\text { The project is developing and testing } \\
\text { promising technologies for reducing } \\
\text { the costs of separating and capturing } \\
\mathrm{CO} 2 \text { from fossil fuel combustion } \\
\text { sources, plus its transport and storage }\end{array}$ & Europe \\
\hline $\begin{array}{l}\text { Power Generation with } \\
\text { CO2 Capture }\end{array}$ & $\begin{array}{l}\text { The project aims to improve the } \\
\text { energy conversion of natural gas in } \\
\text { power cycles that significantly reduce } \\
\mathrm{CO}_{2} \text { emissions. }\end{array}$ & Europe \\
\hline Future Energy Plants & $\begin{array}{l}\text { The project is developing and testing } \\
\text { a concept for co-production of power } \\
\text { and hydrogen from natural gas with } \\
\text { integrated CO2 capture. }\end{array}$ & Europe \\
\hline $\begin{array}{l}\text { Separation of } \mathrm{CO} 2 \\
\text { Using Membrane } \\
\text { Gas/Liquid Contactors }\end{array}$ & N/A & Europe \\
\hline $\begin{array}{l}\text { Advanced Zero } \\
\text { Emissions Power Plant } \\
\underline{(\text { AZEP })}\end{array}$ & $\begin{array}{l}\text { This multi-partner project is } \\
\text { developing an advanced, gas turbine- } \\
\text { based power generation system that } \\
\text { will produce no emissions to } \\
\text { atmosphere }\end{array}$ & Europe \\
\hline $\begin{array}{l}\text { Advanced } \mathrm{CO} 2 \\
\text { Separation and } \\
\text { Geologic Storage } \\
\text { Technologies }\end{array}$ & $\begin{array}{l}\text { The project will demonstrate the } \\
\text { feasibility of capturing } \mathrm{CO}_{2} \text { from a } \\
\text { variety of fuel types and combustion } \\
\text { sources and storing it in unminable } \\
\text { coal seams and saline aquifers }\end{array}$ & North America \\
\hline
\end{tabular}




\begin{tabular}{|c|c|c|}
\hline $\begin{array}{l}\text { CO2 Separation Using } \\
\text { Thermally Optimized } \\
\text { Membranes }\end{array}$ & $\begin{array}{l}\text { Los Alamos National Laboratory and } \\
\text { Idaho National Engineering and } \\
\text { Environmental Laboratory are } \\
\text { collaborating with the University of } \\
\text { Colorado, Pall Corp. and Shell Oil } \\
\text { Co, in a 3-year project to develop an } \\
\text { improved high-temperature polymer } \\
\text { membrane for separating carbon } \\
\text { dioxide from methane and nitrogen } \\
\text { gas streams. }\end{array}$ & Los Alamos \\
\hline $\begin{array}{l}\text { Dry Regenerable } \mathrm{CO} 2 \\
\underline{\text { Sorbents }}\end{array}$ & $\begin{array}{l}\text { The project will investigate and } \\
\text { develop a separation technology that } \\
\text { uses a regenerable, sodium-based } \\
\text { sorbent to capture } \mathrm{CO}_{2} \text { from flue gas }\end{array}$ & North America \\
\hline $\begin{array}{l}\frac{\text { CO2 Dioxide Process }}{\text { for Gas Separation }} \\
\text { from Shifted Syngas }\end{array}$ & $\begin{array}{l}\text { The project will develop a process } \\
\text { that captures } \mathrm{CO}_{2} \text { by combining it } \\
\text { with water at low temperature and } \\
\text { high pressure, thus forming } \\
\mathrm{CO}_{2} / \text { water hydrates }\end{array}$ & North America \\
\hline $\begin{array}{l}\text { A Novel CO2 } \\
\text { Separation System }\end{array}$ & $\begin{array}{l}\text { The project aims to develop a novel } \\
\text { electricity generation and } \mathrm{CO}_{2} \\
\text { separation system based on the } \\
\text { reduction of a metal oxide }\end{array}$ & North America \\
\hline $\begin{array}{l}\text { Vortex Tube Design } \\
\text { and Demonstration for } \\
\text { the Removal of } \\
\text { Carbon Dioxide from } \\
\text { Natural and Flue Gas }\end{array}$ & $\begin{array}{l}\text { The project is studying } \mathrm{CO}_{2} \text {-liquid } \\
\text { absorption kinetics, solvent } \\
\text { generation requirements, and scaleup } \\
\text { parameters for Vortex Tube } \\
\text { contactors }\end{array}$ & North America \\
\hline 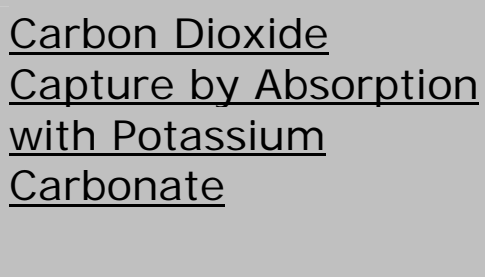 & $\begin{array}{l}\text { The project will develop an } \\
\text { alternative solvent that captures more } \\
\mathrm{CO}_{2} \text { whilst using } 25-50 \% \text { less energy } \\
\text { than conventional, state-of-the-art } \\
\text { MEA (monoethanol amine) scrubbing }\end{array}$ & Austin, Texas \\
\hline $\begin{array}{l}\text { Development of oxy- } \\
\text { fuel boiler concept }\end{array}$ & $\begin{array}{l}\text { The project will develop a novel oxy- } \\
\text { fuel boiler - a new design that } \\
\text { incorporates a membrane to separate } \\
\text { oxygen from the air which is then } \\
\text { used for combustion }\end{array}$ & Tonowanda, New York \\
\hline $\begin{array}{l}\text { Development of } \\
\text { inorganic palladium- } \\
\text { based membranes }\end{array}$ & $\begin{array}{l}\text { The project is developing an advanced } \\
\text { palladium-based membrane for the } \\
\text { reforming of hydrocarbon fuels }\end{array}$ & North America \\
\hline
\end{tabular}




\begin{tabular}{|c|c|c|}
\hline $\begin{array}{l}\text { Development of a } \\
\text { computer model for } \\
\text { the evaluation of } \\
\text { different CO2 capture } \\
\text { from power plant } \\
\text { options }\end{array}$ & $\begin{array}{l}\text { The project is developing a model for } \\
\text { the systematic evaluation and } \\
\text { comparison of different technological } \\
\text { options for } \mathrm{CO}_{2} \text { capture from power } \\
\text { plant }\end{array}$ & Pittsburgh \\
\hline $\begin{array}{l}\text { Detailed cost analysis } \\
\text { of three options for } \\
\text { CO2 capture from an } \\
\text { existing coal-fired } \\
\text { power plant }\end{array}$ & $\begin{array}{l}\text { The project is examining several } \\
\text { technological options for the capture } \\
\text { of } \mathrm{CO}_{2} \text { from coal-fired power plants }\end{array}$ & North America \\
\hline $\begin{array}{l}\text { Research on Physical } \\
\text { Adsorption Method for } \\
\text { CO2 Recovery }\end{array}$ & $\begin{array}{l}\text { The present project forms part of an } \\
\text { on-going programme examining the } \\
\text { Pressure Temperature Swing } \\
\text { Adsorption technique for } \mathrm{CO}_{2} \text { capture }\end{array}$ & Yokosuka, Japan \\
\hline $\begin{array}{l}\text { Development of the } \\
\text { HiOx Technology }\end{array}$ & $\begin{array}{l}\text { The project is developing a power } \\
\text { generation technology whereby } \\
\text { oxygen if firstly separated from the } \\
\text { air, followed by the combustion of } \\
\text { natural gas and concentrated oxygen } \\
\text { in an atmosphere of recirculated } \\
\text { exhaust gases. A concentrated } \mathrm{CO}_{2} \\
\text { stream is produced }\end{array}$ & Norway \\
\hline FutureGen & $\begin{array}{l}\text { A US } \$ 1 \text { billion, } 10 \text { year research } \\
\text { project to build the world’s first coal- } \\
\text { fuelled plant to produce electricity } \\
\text { and hydrogen with zero emissions. } \\
\text { The FutureGen plant will establish the } \\
\text { technical and economic feasibility of } \\
\text { producing electricity and hydrogen } \\
\text { from coal while capturing and } \\
\text { sequestering } \mathrm{CO}_{2} \text { generated in the } \\
\text { process. }\end{array}$ & U.S.A. \\
\hline $\begin{array}{l}\text { Grangemouth } \\
\frac{\text { Advanced } \mathrm{CO} 2}{\text { Capture Project }} \\
\text { (GRACE) }\end{array}$ & $\begin{array}{l}\text { Cost effective environmental } \\
\text { abatement technologies for power } \\
\text { production. }\end{array}$ & UK and Europe \\
\hline $\begin{array}{l}\text { Cooperative Research } \\
\text { Centre for Greenhouse } \\
\text { Gas Technologies } \\
\text { (CO2CRC) }\end{array}$ & $\begin{array}{l}\text { In December 2002, the Australian } \\
\text { Minister for Science announced the } \\
\text { approval of a new Cooperative } \\
\text { Research Centre for Greenhouse Gas } \\
\text { Technologies (CO2CRC). CO2CRC } \\
\text { will undertake research into existing }\end{array}$ & Australia \\
\hline
\end{tabular}


CO2 Capture, Transport and Storage in the Netherlands (CATO)

CASTOR, "CO2 from Capture to Storage" and new capture technologies to reduce the cost of capture and to assess and enhance their suitability for Australian industrial and power generation activities.

Several institutions in the Netherlands Netherlands

have worked on a number of aspects or components of Clean Fossil Fuel (CFF) systems. Often these institutions have very different perspectives but CATO aims to streamline the objectives and perspectives of these activities and integrate them into a comprehensive programme and network, closely connected to international networks in which the partners of CATO participate.

The project's objective is to make possible the capture and geological storage of $10 \%$ of European $\mathrm{CO}_{2}$ emissions, or $30 \%$ of the emissions of large industrial facilities (mainly conventional power stations). To accomplish this, two types of approach must be validated and developed: new technologies for the capture and separation of $\mathrm{CO}_{2}$ from flue gases and its geological storage, and tools and methods to quantify and minimize the uncertainties and risks linked to the storage of $\mathrm{CO}_{2}$. In this context, the Castor project program is aimed more specifically at reducing the costs of capture and separation of $\mathrm{CO}_{2}$ (from $40-60 € /$ ton $\mathrm{CO}_{2}$ to 20 $30 € /$ ton), improving the performance, safety, and environmental impact of geological storage concepts, and, finally, validating the concept at actual sites.

Clean Energy Systems (CES), Kimberlina demonstration plant
CES is a privately funded company based in California that is develop-ing an oxy-combustion process based on
Europe

CES Base at Rancho Cordova CA, USA. Demonstration facility at 


\begin{tabular}{|c|c|c|}
\hline & $\begin{array}{l}\text { rocket propulsion technology. The } \\
\text { company is conducting a series of } \\
\text { developments aimed at demon- } \\
\text { strating a complete oxy-combustion, } \\
\text { zero-emissions power generation } \\
\text { system. The first step involved the } \\
\text { development of a high-pressure gas } \\
\text { generator (burner) that burns natural } \\
\text { gas with pure oxygen in the pres-ence } \\
\text { of a large water recycle to control } \\
\text { flame temperature. The gas generator } \\
\text { produces a mixture of high-pressure } \\
\text { steam and CO }{ }_{2} \text { that drives an } \\
\text { expansion turbine to generate power. } \\
\text { The second part of the development is } \\
\text { to demonstrate the complete power } \\
\text { cycle by adding the turbine, } \\
\text { condensing the steam, recycling the } \\
\text { condensate, and capturing the CO }{ }_{2} \text {. } \\
\text { The final stages of development will } \\
\text { involve developing tur-bines capable } \\
\text { of operating at higher temperatures } \\
\text { and pressures in order to maximise } \\
\text { the efficiency of the power cycle. } \\
\text { Successful tests of up to three minutes } \\
\text { duration have been achieved on a gas } \\
\text { generator of } 20 \text { MW thermal capacity. }\end{array}$ & $\begin{array}{l}\text { Kimberlina Power Plant, } \\
\text { near Bakersfield, CA, USA }\end{array}$ \\
\hline $\begin{array}{l}\text { Enhanced Capture of } \\
\text { CO2 (ENCAP) }\end{array}$ & $\begin{array}{l}\text { The ENCAP project is a research } \\
\text { project for the development of Pre- } \\
\text { combustion technologies for } \\
\text { Enhanced Capture of } \mathrm{CO}_{2} \text { in large } \\
\text { power plants. }\end{array}$ & Europe \\
\hline
\end{tabular}

Figure 10. Carbon capture projects from the IEA Greenhouse Gas Programme database. 
Additionally, the IEA database lists the following 11 "commercial-scale” projects (Figure 11):

\begin{tabular}{|c|c|c|}
\hline Project Title & Project Overview & Location \\
\hline $\begin{array}{l}\text { Shady Point Power } \\
\text { Plant }\end{array}$ & $\begin{array}{l}\text { The plant generates electricity and } \\
\text { produces food-grade } \mathrm{CO}_{2} \text { from flue } \\
\text { gases }\end{array}$ & Oklahoma \\
\hline Sleipner Project & $\begin{array}{l}\text { The storage in underground } \\
\text { geological formations is an attractive } \\
\text { option for the removal, essentially } \\
\text { permanently, of very large quantities } \\
\text { of } \mathrm{CO}_{2} \text { generated from a variety of } \\
\text { industrial operations. One promising } \\
\text { technological option is that of } \\
\text { capturing } \mathrm{CO}_{2} \text { and injecting it into } \\
\text { deep underground saline aquifers, } \\
\text { found in many parts of the world. One } \\
\text { such formation is located above the } \\
\text { Sleipner field, one of the larger } \\
\text { natural gas producers in the North } \\
\text { Sea. }\end{array}$ & Europe \\
\hline $\begin{array}{l}\text { Warrior Run Power } \\
\text { Plant }\end{array}$ & $\begin{array}{l}\text { The plant generates electricity and } \\
\text { produces food-grade } \mathrm{CO}_{2} \text { from flue } \\
\text { gases }\end{array}$ & Cumberland, Maryland \\
\hline $\begin{array}{l}\text { Bellingham } \\
\text { Cogeneration Facility }\end{array}$ & $\begin{array}{l}\text { The plant generates electricity and } \\
\text { produces food-grade } \mathrm{CO}_{2} \text { from flue } \\
\text { gases }\end{array}$ & Bellingham, Massachusetts \\
\hline $\begin{array}{l}\text { Sumitomo Chemicals } \\
\text { Plant, Chiba, } \\
\text { Japan/Kokusai Carbon } \\
\text { Dioxide }\end{array}$ & $\begin{array}{l}\text { The plant generates electricity and } \\
\text { produces food-grade } \mathrm{CO}_{2} \text { from flue } \\
\text { gases }\end{array}$ & Chiba, Japan \\
\hline $\begin{array}{l}\text { Prosint Methanol } \\
\text { Production Plant }\end{array}$ & $\begin{array}{l}\text { The plant uses an MEA-based } \\
\text { scrubber to capture } \mathrm{CO}_{2} \text { from boiler } \\
\text { flue gas for use in beverage } \\
\text { production }\end{array}$ & Rio de Janeiro, Brazil \\
\hline$\frac{\text { IMC Global Inc. Soda }}{\text { Ash plant, Trona }}$ & $\begin{array}{l}\text { Part of this large soda ash production } \\
\text { plant comprises a coal-fired power } \\
\text { generation plant featuring } \mathrm{CO}_{2} \\
\text { capture from the flue gas. The } \mathrm{CO}_{2} \text { is } \\
\text { used for the carbonisation of brine }\end{array}$ & Trona, California \\
\hline
\end{tabular}




\begin{tabular}{|c|c|c|}
\hline $\begin{array}{l}\text { The Indo Gulf } \\
\text { Fertilizer Company } \\
\text { Plant, India }\end{array}$ & $\begin{array}{l}\text { The fertiliser plant incorporates a } \mathrm{CO}_{2} \\
\text { capture facility that feeds a urea } \\
\text { manufacturing unit }\end{array}$ & Jagdishpur, Uttar Pradesh \\
\hline $\begin{array}{l}\text { Luzhou Natural Gas } \\
\text { Chemicals (Group) }\end{array}$ & $\begin{array}{l}\text { The plant produces urea and ammonia } \\
\text { for the fertiliser industry in China. } \\
\text { Part of the plant features a scrubber } \\
\text { system that captures } \mathrm{CO}_{2} \text { from the } \\
\text { process for urea production }\end{array}$ & Luzhou City \\
\hline $\begin{array}{l}\text { Petronas Fertilizer } \mathrm{Co}, \\
\text { Malaysia }\end{array}$ & $\begin{array}{l}\text { The plant features an amine-based } \\
\text { scrubbing system, operating with a } \\
\text { novel solvent, as part of its operations } \\
\text { producing ammonia and urea for the } \\
\text { fertiliser market }\end{array}$ & Malaysia \\
\hline $\begin{array}{l}\text { Great Plains Synfuels } \\
\text { Plant (GPSP) CO2 } \\
\text { Capture and } \\
\text { Compression }\end{array}$ & $\begin{array}{l}\text { The GPSP is the only commercial- } \\
\text { scale coal gasification plant in the } \\
\text { United States that manufactures } \\
\text { natural gas. Located five miles } \\
\text { northwest of Beulah, North Dakota, } \\
\text { the GPSP has been owned and } \\
\text { operated by Dakota Gasification } \\
\text { Company (DGC), a subsidiary of } \\
\text { Basin Electric Power Cooperative, } \\
\text { Bismarck, North Dakota, since } 1988 \text {. } \\
\text { This } \$ 2.1 \text {-billion plant began } \\
\text { operating in 1984. Using the Lurgi } \\
\text { process, the GPSP gasifies lignite coal } \\
\text { to produce valuable gases, liquids, } \\
\text { and byproducts (including } \mathrm{CO}_{2} \text { ). } \\
\text { Delivers } \mathrm{CO}_{2} \text { to the Weyburn Unit in } \\
\text { Canada }\end{array}$ & $\begin{array}{l}\text { Five miles northwest of } \\
\text { Beulah, North Dakota }\end{array}$ \\
\hline
\end{tabular}

Figure 11. Commercial scale carbon capture projects from the IEA Greenhouse Gas Programme database.

The Carbon Capture Project has devoted considerable effort to optimizing the process schemes used for $\mathrm{CO}_{2}$ capture. They selected three cases to evaluate: North European Refining and Petrochemical Complex, Alaska Open Cycle Gas Turbines, and a Norwegian 400MW NGCC power plant. Their study confirmed the ballpark figures for $\mathrm{CO}_{2}$ capture cost - their reference case was set at $\$ 60 /$ tonne of $\mathrm{CO}_{2}$ avoided. Through a series of value engineering and design integrations, estimated avoidance costs were reduced ultimately to $\$ 28 /$ tonne.

\section{Conclusions}

Technology exists to remove $\mathrm{CO}_{2}$ from major stationary sources such as power plants, refineries, gas plants and chemical plants. $\mathrm{CO}_{2}$ is already being removed from natural gas if it is present in the raw gas (about 30\% of natural gas contains significant amounts of $\mathrm{CO}_{2}$ ), but this 
$\mathrm{CO}_{2}$ is vented to the atmosphere except in a few instances where the gas is needed for EOR. Power plants are the most significant source of $\mathrm{CO}_{2}$ emissions in the southwest region. The estimated cost with current technology would result in a nominal $\$ 50$ per tonne $\mathrm{CO}_{2}$ avoided cost. Unless a $\mathrm{CO}_{2}$ emissions tax of this magnitude (or in the alternative an available trading credit) is imposed, utilities will not implement $\mathrm{CO}_{2}$ capture.

New technology under development from numerous parties worldwide will likely lower the cost of $\mathrm{CO}_{2}$ capture. Most such technology is many years away and some may never be realized for a variety of reasons.

IGCC electricity generation is, in many situations, a relatively inexpensive approach to effective $\mathrm{CO}_{2}$ capture in the near-term. Although the cost is slightly higher (and the risk higher) than standard PC power plants, utilities are now beginning to include these in their generation forward planning since they provide a hedge against future emissions regulations more stringent than today's (whether including $\mathrm{CO}_{2}$ emissions requirements or not). Additional implementations of IGCC in several utility territories will increase the broad acceptance of this approach and should be encouraged by government incentives.

Many of the new, advanced technologies which can potentially offer lower-cost capture will require field experiment testing and demonstrations. These technologies will be screened in the southwest region in conjunction with the region's source/sink database to identify a suitable candidates for Phase II projects. The baseline information described above is essential to identify current opportunities for $\mathrm{CO}_{2}$ capture in the region and to determine, when coupled with cost information or estimates for the new technology, the most promising options compared to current state-of-the-art technology.

\section{Brief Summary of Database Associated with Subtask 1.4: Description of GIS Database}

\section{Developed and Implemented by the Southwest Partnership}

Compilation of the GIS layers for the southwest partnership is progressing reasonably well. It has been difficult to complete a data model for some layers, in particular the geologic sinks, but this appears to be very close to a solution.

The establishment of a test case scenario has helped a great deal toward clarifying these data needs. The application of the modeling group's concepts to a small area in the partnership region has had the effect of narrowing the experts in on those GIS layer attributes that are really the most useful for a project of such a large spatial extent and combining GIS layers from disparate sources.

The data layers to include and the attributes they should contain are decisions that are being made by the modelers in conjunction with the partners in the respective source, sink and transport groups. The data models are dependent, not only upon the needs of the modeling effort, but also upon the availability and suitability of existing data where partners are not able to create new data. In addition, AGRC has compiled a set of base layers that provide a good foundation for the presentation of the source and sink data as well as adding to the modeling process.

Below is a list of layers or groups of layers that are to be included in the database along with a description of their status. 


\section{Base Layers}

Included under the base layers heading are layers such as roads, railroads, populated places, demographics, drainage, and elevations. These layers are in the database now, or can be quickly obtained and added.

\section{Land Ownership}

A small scale land ownership layer prepared by BLM is in the database. We also have largerscale land ownership by individual state that can be added to the database. These layers separate out all major categories of federal land ownership. They also show areas of state as well as private ownership.

\section{Geologic Sinks}

The geologic sinks have proven to be the most difficult layers as far as defining the attributes needed for an effective modeling effort to be made. With the exception of Wyoming, Kansas and Texas, all the states in the partnership have provided preliminary data sets along with the GASIS database with keys to each oil and gas field. Efforts have been made to obtain data sets from these states and the data appears to be available from them. The core attributes needed by the modelers seem to have been preliminarily decided upon. It is intended that these core attributes will be formalized in the Oil and Gas fields data model shortly. Members of the geologic working group have indicated that these attributes should, in most cases, already be part of the GASIS database to which the GIS layers will be linked.

No saline aquifer data has been provided at this time, nor has a data model been formalized. There has been discussion about the direction of the modeling efforts in this area however.

\section{Point Sources}

$\mathrm{A} \mathrm{CO}_{2}$ point source layer has been compiled based on data provided by NATCARB. This layer consists of point sources provided by EPA and EGRID. This layer has some obvious flaws in the placement of many of the points. GTI has provided a list of additional point sources, but only those that portray the same points as the EPA/EGRID data have $\mathrm{CO}_{2}$ emissions as an attribute. New Mexico and Colorado have provided point source data that will be used to help clean up the EPA/EGRID data. AGRC can perform some limited cleanup on other areas.

\section{Terrestrial Sinks}

No terrestrial data has been submitted. It is anticipated that the GIS layers that have been created by the partners working on terrestrial sinks will be provided to AGRC for inclusion in the database.

\section{Pipelines}

Pipeline layers are tightly controlled by those who have recent data. There is a detailed layer created by the US Department of Transportation that requires an application be made that includes an assurance that access to the data will be controlled.

The major remaining tasks as far as the database is concerned are still the completion of the geologic and point source data models and the manipulation of the existing source and geologic sink layers to fit within that model. Hopefully, the geologic sink attributes that have been settled upon for the test case scenario are in the existing state databases. This should be the case 
according to some of the partners in the sinks group. If better source data cannot be located, the worst-case scenario is that the EPA/EGRID data will be usedwith few modifications.

\section{Task 2: Identify and Address Sequestration Implementation Issues}

\section{Summary Discussion of Subtasks 2.1 and 2.2}

Summary of Regulatory and Permitting Requirements for Sequestration in Southwest Region

Regulatory requirements for the use of $\mathrm{CO}_{2}$ into oil and gas reservoirs are in place for enhanced oil and/or gas recovery. These projects are well established in states having oil and gas production through both Federal and State underground injection control (UIC) programs. Some modification will be necessary for the long-term retention of injected $\mathrm{CO}_{2}$ at the end of the productive life of the hydrocarbon reservoirs. The storage of natural gas in subsurface strata is a well established process. Not all states, such as New Mexico, have established regulatory processes for the characterization of gas storage reservoirs. Permitting by regulatory commission orders have been used on a case by case basis, however, for the long-term storage (sequestration) new rules and regulations will be necessary. The rule making process varies among states and time required to establish such regulations will vary greatly. Several years ago an Interstate Oil and Gas Compact Commission (IOGCC) Task Force developed a "Gas Storage Regulatory" model that can be utilized by state regulatory agencies as a guideline for developing long-term storage of $\mathrm{CO}_{2}$. The recent IOGCC $\mathrm{CO}_{2}$ Task Force, in conjunction with the various regional partnerships, developed a report addressing a number of regulatory issues for the implementation of $\mathrm{CO}_{2}$ long-term storage (sequestration). The information provided in this report can be used by the various states as a substantial step forward in addressing potential regulatory issues. In summary, various regulatory issues remain to be addressed by all the Partnership states before long-term storage (sequestration) can be fully implemented. We will evaluate the specific regulatory constraints and gaps associated with each Southwest Phase II option site (summarized in the Executive Summary of this report), and include these in the integrated assessment analysis (described later in this report) and ranking of the Phase II pilot options.

\section{Summary of Risk Assessment for Potential Geologic Sequestration Sites}

The Partnership MMV team (described in following section) has been developing a comprehensive risk-assessment framework, including a systematic methodology for assigning risk factors to apply in the integrated assessment model (described in subsequent sections of this report). We are basin these methods on previous studies, including the recently released IEA GHG Weyburn Monitoring and Storage Project Summary Report 2000-2004, published by the Petroleum Technology Research Centre of Canada, and the wealth of previous studies published by the U.S. Department of Energy.

At the current time, we have assembled a general approach for evaluating and assigning risks associated with geologic sequestration options. We will develop specific frameworks for each Phase II site option, tailored for the unique geology and engineering details associated with each option. These tailored risk protocols will be outlined in detail within the action plans developed for our Phase II pilot test options, to be delivered to NETL in the coming months. 
Summary Discussion of Subtask 2.3

\section{Major Goals}

\section{Summary of Year 1 Measuring/Monitoring/Verification (MMV) Efforts}

1) To determine the needed equipment/technology to assess the $\mathrm{CO}_{2}$ containment ability of varying reservoirs (oil/gas, saline, coalbed), including direct and indirect approaches.

2) To determine the cost of varying technologies that can be applied for MMV.

3) To determine the compliance structure that needs to be taken for MMV deployment (e.g., regulatory compliant, risk assessment, liability, and public outreach).

General Research Questions Considered

1) What does DOE currently require for $\mathrm{CO}_{2}$ containment in existing reservoirs?

2) What do the specific states require for $\mathrm{CO}_{2}$ containment?

3) What is the current infrastructure for MMV technologies (e.g., pressure tests at well bore)

4) Is the current MMV technologies enough?

5) How can we improve the MMV technologies?

a. What is the temporal and spatial sampling strategy

b. How will this change for reservoir type and state?

c. How will this change with population/infrastructure?

6) What sites are optimum for a Phase II pilot site, keeping MMV in context, i.e., how will MMV considerations affect site choice?

a. What are our options? (map of existing sites)

b. Choose location away from population, parks, public places

c. How should we outfit the site, what first approaches should we use?

7) How do we remain compliant?

a. Litigation-who is responsible, how will this change over time

b. Regulation-tools needed to regulate, checks and balances

c. Risk assessment-standard protocols used or blanket risk analyses performed and by whom?

d. Longevity-who pays for MMV in future, who pays for regulation and risk assessment in future?

8) How do we convey MMV technology, regulation, risk assessment to the public?

a. Outreach programs

b. Public lectures

c. Education classes

d. Site tours

The Southwest Partnership’s MMV Working Group

We assembled a strong research team for the MMV tasks of the Partnership, consisting of scientists and engineers with MMV expertise and field experience, including the direct $\mathrm{CO}_{2}$ surface flux approaches proposed here. Collaborators on this project have served as core MMV specialists on other major $\mathrm{CO}_{2}$ sequestration projects. The team is composed of collaborators across the Partnership, including personnel from New Mexico Tech, the Utah Geological Survey, Los Alamos National Laboratory, as well as a strong industry participants that include Kinder Morgan, Tucson Electric Power, and Ridgeway Petroleum. 
Summary of Direct Approaches (Surface Gas Monitoring) Under Current Evaluation by the Partnership

One of the most major concerns associated with geologic sequestration is verification of containment (storage) and ability to detect any migration of $\mathrm{CO}_{2}$ from the storage reservoir to the surface, even if only slight. A comprehensive measurement, monitoring, and verification (MMV) plan must be established for the ultimate pilot deployment site(s), tailored to meet its specific geology and surface attributes. Some aspects will be common to all geologic sequestration sites. For instance, constant monitoring of $\mathrm{CO}_{2}$ concentrations in air, water and/or soils is a primary requirement.

Direct measurements of $\mathrm{CO}_{2}$ concentrations at the surface and in wells will be required. If constant monitoring of background levels over the area suggests that $\mathrm{CO}_{2}$ has migrated from the storage reservoir to any point at the surface, even if small, then higher-resolution equipment (e.g., point-focused eddy flux towers) may be set up to track specific changes, and to help determine whether the injection schedule needs altering.

Sensors for Direct $\mathrm{CO}_{2}$ Measurements at Surface

Sensor technology for monitoring $\mathrm{CO}_{2}$ is already in place in the petroleum and other industries, including such routine tasks as automobile emissions measurements, and specialized applications such as monitoring carbon dioxide concentrations for worker safety (such as at $\mathrm{CO}_{2}$ EOR facilities and cement or other chemical processing plants).

Mass spectrometry is the most accurate method for measuring $\mathrm{CO}_{2}$ concentration, but it is not a portable approach. As discussed by Benson and Myer (2002), most portable devices use infrared technology, and are referred to as infrared gas analyzers (IRGA). Many IRGAs use nondispersive infrared (NDIR) or Fourier Transform infrared (FTIR) detectors (Benson and Myer, 2002), evaluating light attenuation by $\mathrm{CO}_{2}$ at a specific wavelength. Costs may influence what type is used in a given setting, but also regulatory aspects and compliance as mandated by OSHA, the EPA, or other agencies.

In ongoing and previous projects, different personnel in the Partnership have measured $\mathrm{CO}_{2}$ concentrations in soil air (Hendrickx, Phillips and Harrison, 2001), flux from soils (Allis et al., 2004; Heath, 2004), and ecosystem-scale carbon dynamics (e.g., evapotranspiration; Hendrickx et al., 2001) . Diffuse soil flux measurements are made using simple IR analyzers (Oskarsson et al. 1999). Sorey et al. (1996) of the USGS measure $\mathrm{CO}_{2}$ fluxes for various projects using "LICOR” detectors, which are differential, non-dispersive gas analyzers. The Partnership is considering several MMV technologies for possible deployment at pilot test sites, including in situ diffuse $\mathrm{CO}_{2}$ flux (IDF) technology -- a state-of-the-art commercial infrared gas analyzer (IRGA), capable of surveying soil gas fluxes from patches at scales of order 100-500 cm2. Such IRGAs are calibrated at the start of a field survey using $\mathrm{CO}_{2}$-free air and $1000 \mathrm{ppm} \mathrm{CO}_{2}$ standards. Experience with using these devices suggests uncertainties are better than $1 \mathrm{ppm}$ when the instrument is well-calibrated. $\mathrm{CO}_{2}$ measurements are made by placing an accumulation chamber (AC) on the soil surface and pressing it into the soil to obtain a seal. AC gases are pumped through a desiccant to the IRGA and are returned to the AC in a closed loop. Another possible technology is Eddy-flux correlation (ECOR) technology - fully automated, towermounted, open path $\mathrm{CO}_{2}$ sensors. The sensors in ECOR towers also use LICOR-8100 type technology, but are tower mounted, measure fluxes of both $\mathrm{CO}_{2}$ and $\mathrm{H}_{2} \mathrm{O}$, and use 3-D sonic anemometers that monitor wind velocities. The most common application for ECOR towers are for evapotranspiration measurements at and above the surface, by deriving $\mathrm{CO}_{2}$ and $\mathrm{H}_{2} \mathrm{O}$ fluxes at high frequency using the eddy-flux correlation technique. In contrast to IDF, the ECOR 
towers are capable of measuring soil-atmospheric gas fluxes at scales of 20 to $200 \mathrm{~m} 2$ (see Dubey et al in DOE's AMERIFLUX tower web site 2004, http://public.ornl.gov/ameriflux/Site_Info/siteInfo.cfm?KEYID=us.valles_caldera.01)).

One reason the Partnership is considering these differing technologies is because they measure $\mathrm{CO}_{2}$ fluxes in different ways - specifically, IDF measures fluxes at the soil surface by placing a chamber on the soil and monitoring the rate of accumulation of $\mathrm{CO}_{2}$ in this known volume. This provides a direct measure of diffuse $\mathrm{CO}_{2}$ fluxes from the surface, especially baseline or background fluxes, consisting of both $\mathrm{CO}_{2}$ fluxes from below the soil horizon and biogenic fluxes in the soils. The size scale is determined by the area at the soil chamber interface and is typically of order $500 \mathrm{~cm}^{2}$. The IDF instrument allows for "stacked" measurements in order to arrive at an average value for a particular site. The ECOR towers, on the other hand, operate in the open air and can measure broad background fluxes over much larger areas (20-200 $\mathrm{m}^{2}$ ) as well as assess whether "point" fluxes of greater magnitude exist in a given area. They work on the principle that when sufficient wind-induced turbulence exits the covariance of the local vertical wind velocity and carbon dioxide, both measured at high frequency, the vertical flux of carbon dioxide may be deduced.

\section{Well Monitoring}

Water and gases in all available wells at the ultimate pilot site(s) will be monitored, if possible. This includes injection wells, groundwater wells, and any abandoned/plugged wells.

\section{Geochemical Methods and Tracers}

Characterizing the geochemical evolution of sampled gases and groundwaters in the vicinity of the pilot test site(s) will help monitor plume migration and for determining the extent of diagenetic changes occurring. Typically, major ions (e.g. $\mathrm{Na}, \mathrm{K}, \mathrm{Ca}, \mathrm{Mg}, \mathrm{Mn}, \mathrm{Cl}, \mathrm{Si}, \mathrm{HCO}_{3}-$ and $\left.\mathrm{SO}_{4}\right) \mathrm{pH}$, stable isotopes (e.g. 13C, $14 \mathrm{C}, 18 \mathrm{O}, 2 \mathrm{H}$ ), especially $\mathrm{CO}_{2}$ and its associated isotopes, are evaluated (Heath, 2004). Benson and Myer (2004) discuss how natural tracers (isotopes of C, $\mathrm{O}, \mathrm{H}$ and noble gases associated with the injected $\mathrm{CO}_{2}$ ) and introduced tracers (noble gases, SF6 and perfluorocarbons) are used to track underground migration of $\mathrm{CO}_{2}$ and associated reactions with geologic strata.

\section{Numerical Simulation Models}

As discussed previously, investigators within the Partnership have already developed numerical models of several pilot test sites under consideration for Phase II. These models simulate coupled subsurface heat flow, fluid flow, and reactive transport within the geologic units of these sites, the Springerville-St. Johns site (Allis, et al., in prep) and the Crystal Geyser area site (Heath and McPherson, 2004). These models use well-known simulation packages, including CHEM-TOUGH, jointly developed by Stephen White and Lawrence Berkeley National Laboratory and FLOTRAN, developed by Peter Lichtner and others at Los Alamos National Lab.

The latest field evidence and results from recent studies indicate that mechanisms of shallow $\mathrm{CO}_{2}$ flux from known $\mathrm{CO}_{2}$ systems are proving to be complex. Thus, methods for detecting and monitoring soil $\mathrm{CO}_{2}$ fluxes need to be practical, adaptable, portable, and probably simple-large areas may have to be surveyed in order to be confident that no gas leakage occurs. Effective MMV technologies are absolutely essential to ensure the safety and success of long-term 
geologic sequestration operations. At this point in time, many different MMV protocols are available for direct measurements of $\mathrm{CO}_{2}$ fluxes at the earth's surface.

Prior Research and How It Relates to this Proposed Project

Previous studies of the Crystal Geyser-Ten Mile Graben area have been conducted by investigators in the Partnership. For a separate study, a soil gas survey was carried out in October, 2004, in the Crystal Geyser-Ten Mile Graben area (under final year of contract DEFC26-00NT40926, co-PI Rick Allis of the UGS), where there is an unstable discharge of $\mathrm{CO}_{2}-$ rich fluids, and the results are being used to assist the Partnership's efforts. Other Partnership personnel, in separate studies, have been studying the Springerville-St. Johns $\mathrm{CO}_{2}$ system, where 30 measurement sites in an area of several hundred square kilometers showed no anomalous gas flux, but field evidence indicate that four groundwater wells fluctuate in $\mathrm{CO}_{2}$ flux in correlation with barometric pressure changes, and a spot $\mathrm{CO}_{2}$ measurement on one well showed $15 \% \mathrm{CO}_{2}$. In addition to gas discharges, water samples from wells show high bicarbonate concentrations (> $1 \mathrm{~g} / \mathrm{L}$ ). This is similar to the high bicarbonate concentrations in the wells and springs of the Crystal Geyser-Ten Mile Graben area (Heath, 2004). There is also evidence from 20 years of $\mathrm{CO}_{2}$ injection near Rangely, $\mathrm{CO}$ (Klusman, 2003) that bicarbonate concentrations in wells has increased, but no surface flux has been detected. Results of all of these separate studies are being used to guide the Partnership’s MMV efforts, as is the current literature.

Summary Discussion of Subtask 2.4: Action Plan for Addressing Environmental Efficacy and General Sequestration Implementation Requirements: the Integrated Assessment Model Approach

\section{Integrated assessment activities to date}

An Integrated Assessment Committee (working group) was assembled for the purpose of developing a rigorous approach or framework for establishing and communicating the consequences and tradeoffs between alternative $\mathrm{CO}_{2}$ emission reduction strategies. This framework will also be used for comparing all Phase II pilot test options for the Partnership, discussed in the Executive Summary. This is required for formulating an effective and publicly acceptable sequestration program. Several activities are completed or ongoing to support development of the regional integrated assessment framework. Each is discussed below.

Development of the regional model: The integrated assessment is based on a system-modeling decision framework that provides the means to compare alternative sequestration approaches. The model tracks the regional temporal dynamics of:

- Energy consumption

- $\mathrm{CO}_{2}$ emissions by source

- Costs of $\mathrm{CO}_{2}$ capture, separation, transport, and sequestration for alternative $\mathrm{CO}_{2}$ source/sink combinations

- Amount of $\mathrm{CO}_{2}$ sequestered

The regional model has been developed using key components from the Sandia National Laboratories U.S. Energy and Greenhouse Gas Model (USEGM). The USEGM has been adapted to the Southwest region, and is represented as the blue elements of the integrated 
assessment framework shown in Figure 12. The red elements shown in Figure 12 are currently being developed in collaboration with the Geologic Sinks and the Physical Infrastructure and Sources Committees. This activity is discussed below.

In order to "regionalize" the USEGM, the following items were delivered/researched for the model integration efforts:

1. Energy Statistics for the United States, Arizona, Colorado, New Mexico, Oklahoma, and Utah:

a. Total Energy Consumption by Economic Sector

i. Residential

ii. Industrial

iii. Commercial

iv. Transportation

b. Total Electricity Consumption by Fuel

i. Coal

ii. Geothermal

iii. Hydropower

iv. Natural Gas

v. Nuclear

vi. Other renewables

vii. Petroleum

viii. Wood and Waste

2. $\mathrm{CO}_{2}$ output by source (EGRID database)

3. Prototype model and interface for the southwest region

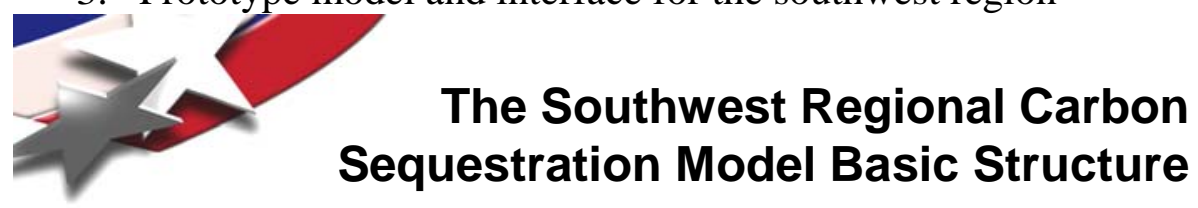

SAND OHP 04-26-2004

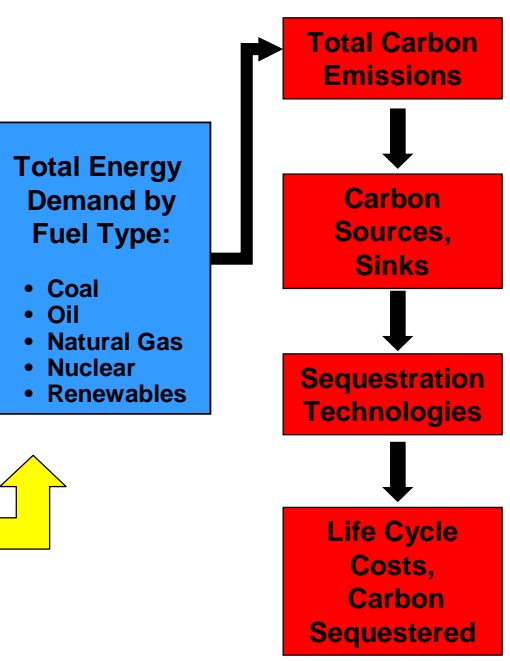

Figure 12. Sequestration model basic structure. 
Establish a test case in NM and CO counties: In order to move forward on construction of the regional assessment framework, the Partnership selected a test area in the region. Application to the test area allows development of the model while the databases to support analysis of the full Southwest region are under development. The San Juan basin in Northwestern New Mexico and Southeastern Colorado was selected for the test area. The counties selected are:

CO: Montezuma, La Plata, and Archuleta

NM: San Juan

General features of these counties are illustrated in Figure 13.

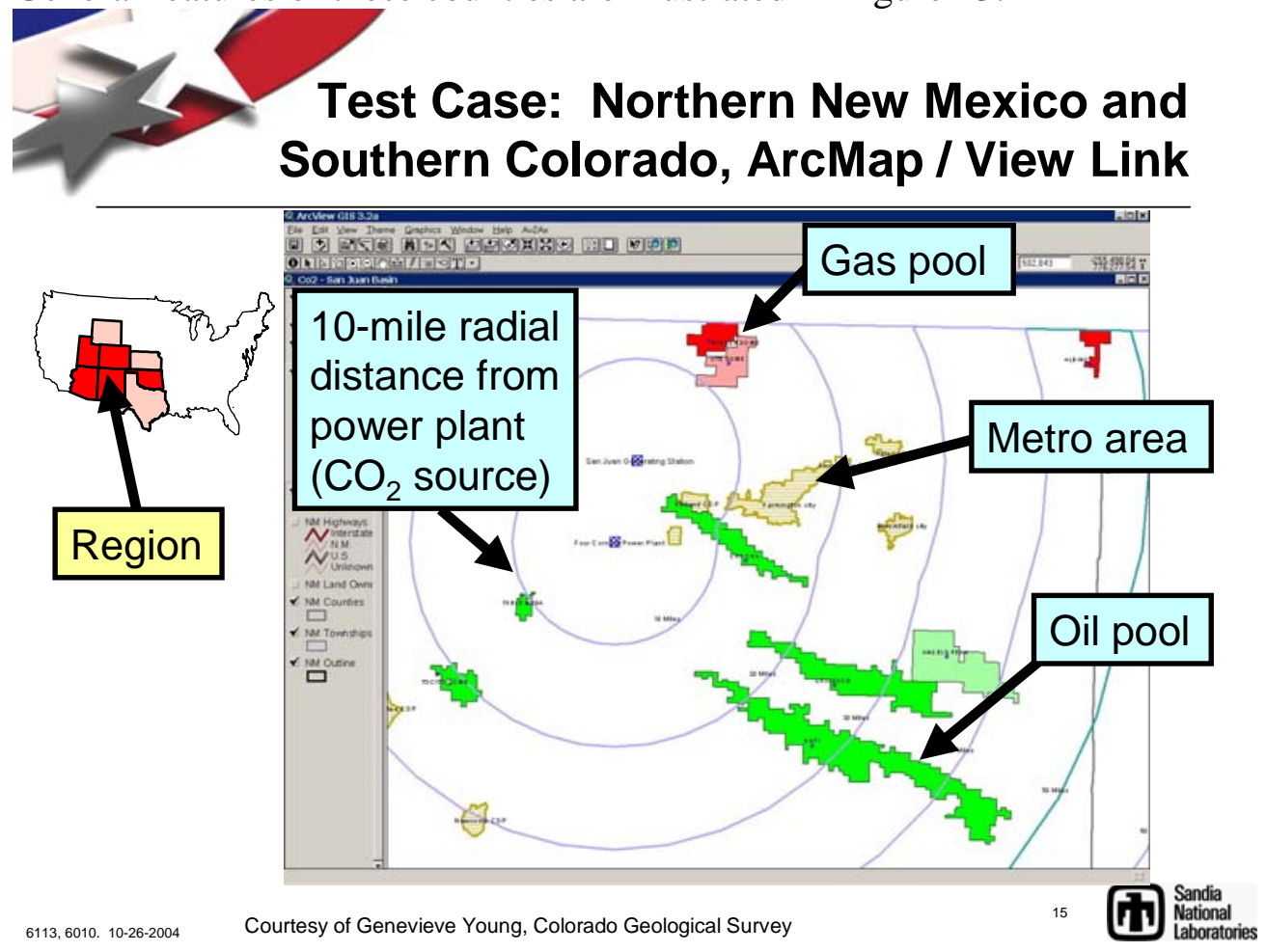

Figure 13. Map of test area showing general features, as indicated (this is an actual screen shot from the database interface screen).

Initially five $\mathrm{CO}_{2}$ emissions sources - all coal-fired electric power plants - have been selected from the EGRID database for the test case. Seventeen sinks have been identified in the test area, although others may yet be included. The sinks selected for the initial test area application are drawn from existing oil and natural gas reservoirs, since the available geologic data is most complete for these types of geologic sites. Additional sources and sinks in the test area will be included once the integrated assessment framework has been fully established.

Collaboration with Geologic Sinks and Physical Infrastructure and Sources Committees: The Integrated Assessment Committee has worked closely with the members of these committees to develop characterization of the $\mathrm{CO}_{2}$ sources, the geologic sinks, and the costs associated with sequestration options in the test area that can be linked to the regional model. Sources are characterized by annual $\mathrm{CO}_{2}$ emissions, power plant efficiency, age of plant, and location. Sink characterization includes location, depth, volume, injectivity, and risk of leaks (based on 
geologic features). Distances between sources and sinks are calculated using a great circle distance (GCD) formulation.

Establish initial sequestration cost equations for oil and NG fields: Cost equations for $\mathrm{CO}_{2}$ separation, collection, transport, and injection based on emissions volumes have been developed based on information collected from relevant literature, and verified by members of the Physical Infrastructure and Sources Committee. These equations have been used to develop prototype cost algorithms for the regional integrated assessment model, which are being evaluated for the test area.

These model developments have been vetted in workshops and web conferences to increase understanding of the model by external parties, and to get input on desired interfaces - what elements of the model are accessible by users to explore different "what if" questions about sequestration alternatives. Two workshops and two web-based conferences have been held, involving individuals from the electric power industry and state regulatory agencies. In addition, the integrated assessment framework was presented for discussion at the Third Annual Conference Carbon Capture and Sequestration in May 2004, and members of the Integrated Assessment Committee met with staff at NETL to discuss sequestration options and costs.

\section{Projected activities}

Future activities include completion of the integrated assessment framework, additional public outreach activities, development of monitoring and verification measures and criteria, and extension of the assessment framework to the complete Southwest Region.

Complete the prototype assessment model: The prototype integrated assessment application in the test area will be completed for use in the next workshop in January 2005. As noted earlier, proceeding with the test area allows construction of the integrated assessment model while data collection for the full SW region continues.

Additional Public Outreach Activities: The January workshop will be used to determine the appropriate user interface through project team interactions, and feedback from workshop participants and other external sources. The prototype model will also be used to compare different source/sink combinations in the test case region, and to aid in selection of monitoring and verification criteria. Additional public outreach will be needed as the integrated assessment framework moves from the test area to the Southwest region as a whole, which will involve other external groups in the region.

Development of Monitoring and Verification Functions: The integrated assessment framework will be completed once measures and criteria for monitoring and verification of sequestration sites are established in the prototype assessment model, or developed for application outside the model framework.

Extension of the Integrated Assessment Framework: Once the monitoring and verification elements are included, the integrated assessment model will then be ready to use to compare sources and sinks throughout the SW region as the data become available. 
The source/sink comparisons, using the screening criteria, will establish a set of potential pilot program sites. The set of potential pilot facility sites will require more detailed site-specific evaluation to select a proposed pilot sequestration source/sink system.

Operation of the regional model through time will provide estimates of carbon intensity in the SW region, based on projected economic growth, population growth, energy efficiency in use, and associated energy consumption. These estimates will give high-level calculations about reducing carbon intensity in the Southwest Partnership region by the national goal of $18 \%$ by 2012, depending on different "what if” considerations and associated policy implications.

\section{Task 3: Assess and Initiate Public Outreach/Acceptance}

\section{Summary Discussion of Subtasks 3.1-3.4}

Summary Report of Year 1 Outreach Efforts

Overall, the goal of the public participation process is to develop opportunities for various interest groups (industry, utility, environmental advocates, and environmental policy decisionmakers, and scientists) to collaborate on the implementation of carbon capture and sequestration.

As is the case with many environmental public policy processes, the Southwest Regional Partnership on Carbon Sequestration is a complex situation involving multiple stakeholders. The interests of these stakeholders must be recognized if the Southwest Partnership is to successfully integrate best science and practice (Daniels \& Walker, 2001).

Each stakeholder group has varying levels of and interests for participation in the process. The negotiation among their interests is thoroughly integrated into the outreach plan for participation. Furthermore, these various interests groups enter the carbon sequestration process with differing degrees of scientific background, which impacts their ability to participate (Kinsella, 2004). This presents a challenge to public participation for the integration of science and practice to be both feasible and desirable (Daniels \& Walker, 2001).

To meet this need, the outreach committee of the Southwest Partnership on Carbon Sequestration has implemented two public participation processes, mediated modeling and website design. These processes have occurred relatively separate from one another, as distinct efforts to contact and serve sometimes similar and sometimes different publics; taken together they substantiate a broad-based approach to public outreach and education. Below we report the objectives, process, and results of these two programs beginning with mediated modeling.

\section{Mediated Modeling}

The objective of these modeling efforts is to develop a working model of sources, capture, storage, and sequestration issues in the Southwest Region. Given this applied focus, the model needs to be useful to industry participants, policy makers, and other decision makers regarding carbon sequestration. The modeling, then, is an integration of best science and best practice. To this end, the outreach committee has formed a series of workshops and on-line meetings to collaborate between multiple stakeholder and interest groups. The mediated modeling process began at the January, 2004 workshop in Salt Lake City, continued at the June, 2004 workshop in Albuquerque, and is still in process with a series of on-line meetings in preparation for the final workshop in Albuquerque, 2005. 


\section{Workshop 1}

Objective: The objective of the first workshop was to join scientific and various publics (industry and local stakeholders) in an effort to conceptualize sequestration issues in the Southwest Region.

Process: Consistent with mediated modeling processes, the first session included information presentations given by experts in various fields, including carbon sources and capture technology; sinks and sequestration, including various terrestrial and geological options; and data needs and availability, including GIS and modeling processes.

With these presentations as information sources, participants were then divided into groups and discussed the key aspects of implementing sequestration in the Southwest Region. After thoroughly discussing their respective and similar vantage points, groups developed conceptual models of these issues. This initial step encourages cross-disciplinary communication as the groups are comprised of people from different sectors-e.g., a team is likely to contain a geologist, various industry experts, and an environmental advocate.

After coming to agreement on this group model, each group presented their model to the entire group. The large group then discussed similarities and differences between the various models. This secondary step encourages a better understanding of the desirability and feasibility of various aspects of sequestration.

Results: The models developed at this workshop were transferred into Stella $\subset$ modeling software and presented again to the participants at the June workshop in Albuquerque, New Mexico. This provided continuity to the modeling process and served as a starting point for workshop 2.

\section{Workshop 2}

Objective: The objective of Workshop 2 in Albuquerque was to move from conceptual modeling to more substantive and specific modeling of sequestration issues. Working in conjunction with the modeling committee from Sandia Laboratories in New Mexico, our purpose was to get participants to begin modeling sequestration using computer modeling softwarePowerSim@.

Process: The two-day workshop was a collaborative effort between the modeling and outreach committees with the outreach committee providing the tutorials on systems modeling and facilitating the workshop and the modeling committee overseeing specific modeling issues and helping participants move toward a better understanding of how to model.

The beginning of the first day was spent on modeling tutorials. Modeling software is useful but only after participants develop an understanding what the icons of the software represent.

After the tutorials were complete, the outreach team made available the conceptual models developed in Salt Lake City. Participants then formed groups and spent the remainder of the first day and the beginning of the second day developing models using PowerSim.

In the last portion of the second day, Leonard Malczynski-the modeler with whom the outreach committee organized this workshop-took all four group models and connected them to create a single model. Consistent with mediated modeling processes, this was done with 
significant feedback from and discussion among participants. For example, one discussion brought about by an industry participant focused on the difference between modeling energy consumption and energy production. This discussion ensured greater legitimacy to issues the model focused on and, in turn, the likelihood it would serve as a useful decision tool as the Southwest Partnership for Carbon Sequestration completes Phase I and begins Phase, as well as other decision makers examining the prospects of sequestration in this region.

Results: This workshop was of significant import as it provided a bridge between the conceptual modeling of workshop 1 and the continued development of the model in preparation for workshop 3. Specifically, two things were gained from this workshop: First, a model was developed which a broad-range of participants (e.g., environmental policy experts, coal, and energy/utility company representatives) agreed traced the key aspects of capture, transfer, sequestration, and storage. Second, participants were engaged and committed enough to the process that they volunteered to continue working on the model between workshops 2 and 3 .

\section{Preparing for Workshop 3}

The model which emerged from workshop 2 was qualitative in nature and needed considerable data before it would be of substantive value. The modeling was scheduled to be completed for Workshop 3, January, 2005 in Albuquerque.

Objective: The objective between Workshops 2 and 3 was to facilitate communication between participants and partners (specifically the participants from Workshop 2 and the modeling team at Sandia Laboratories in New Mexico) to continue building the Carbon Sequestration model. The difficult aspect of this need was that participants and partners were dispersed throughout the Southwest Region.

Process: Working in conjunction with New Mexico State University and Tom Freelove of WERC - a consortium for environmental education and technology development-we utilized WERC's on-line webcast software Centra. Centra has been useful both from a public participation and a modeling standpoint because (a) it allows the modeler to present the model, (b) engages all in a discussion of the model's parameters and data, (c) enhances participants' ability to make alterations to the model while in session (using application share, the modeler and participants can alter the model on-line), and (d) permits participants and modelers to view the Centra meeting after it has ended as the sessions are recorded.

Results: We have thus far conducted two of the three Centra meetings and will conduct the last of these meetings on November 15 . These meetings have been particularly useful because it provides an opportunity for participants to give feedback to the modeling committee very quickly after they make alterations to the model. In turn, it allows the modeling committee to respond quickly to participants' questions and suggestions. At the close of the October 4 meeting, for example, one participant sent the modeler some suggestions regarding GIS data that would be needed to connect geological issues to economic concerns in an effort to discriminate between sequestration options. This suggestion was taken into consideration in the model building presented in the November 1 meeting, and all participants agreed to the changes. 
Website Development and Implementation

http://www.southwestcarbonpartnership.org/

The goal of the Southwest Regional Partnership on Carbon Sequestration website was to utilize the World Wide Web as a medium to communicate information on the issue of carbon sequestration to internal and external project stakeholders. The website, http://www.southwestcarbonpartnership.org/, was a part of the larger public participation initiative to engage stakeholders.

Objective: The objective of the website design phase was to create a website that communicates scientific information in an accessible manner and to design the website in a way that allows the user to easily get the information they need.

Process: The development of the Southwest Regional Partnership on Carbon Sequestration website was informed by a review of existing websites on the topic of carbon sequestration, and similar topics such as energy. The existing websites provided information on what works and what does not work in terms of communicating information on carbon sequestration. The information from this website review was communicated to the principle stakeholders to assist them in understanding some of the design implications for the Southwest Regional Partnership on Carbon Sequestration website. The term principle stakeholders is used here to describe those individuals and agencies that are responsible for meeting the objectives and milestones outlined in the Department of Energy grant application.

Meetings were set up with the principle stakeholders to go over their interests and concerns regarding the website. If a principle stakeholder was unable to attend a meeting, he or she received updates via email regarding what was discussed. The initial meetings were an opportunity to understand some of the users of the website. These meetings occurred prior to writing content for the site and its web pages. Communication occurred with the host of the website, the state of Utah, Information Technology Services (ITS) data center regarding the requirements for the web layout and content. The ITS department is responsible for maintaining the website on their server.

Once there was an understanding of the scope and overall goal of the website, categories were developed for the website. These categories were approved by the principle stakeholders prior to writing text for the website. The categories were consistent will the goals of the project overall and with the principles of the public participation plan for the project. Writing text for the website was the next step, and this process was informed by the review of the existing websites, the views and messages of the funding agency, and the goals of the principle stakeholders. The overall goal of the website, category construction, and the content were combined in the development stage of the website. The development and implementation of these elements were consistent with the principles of human-computer interface design and usability. Changes and modifications will be made to the website based upon the users' experiences.

Results: The website design and implementation went well. The design and writing of copy occurred January through March 2004, and the website was functional by April, 2004. Feedback from project partners was very positive about the website and its functionality. There were a few problems with implementing the "Partners Only" web page but these issues were resolved by 
June 2004. One page, "Industry," has not been populated with text, but the primary reason is that that information is covered by other web pages within the website.

The website was advertised to both the internal and external audiences through email, meetings, and the workshops. The website was reviewed on a weekly basis, and updates will be posted as needed. The website is used to disseminate information about the workshops. Agendas and presentations are posted under the "Workshops/Get Involved" page. News stories and other current information are posted on the homepage and also on the "Carbon in the News" page, in an effort to maintain interest in the issue of carbon sequestration in relationship to climate change. Project partners are also encouraged to contribute to the website and provide updates.

\section{Townhall Meetings}

On September 2, 2004, a “townhall meeting” sponsored by the Southwest Regional Partnership on Carbon Sequestration took place on-line, utilizing the CentraOne Symposium provided by WERC at New Mexico State University. The Centra web-based system made it possible for 35 representatives of the gas and oil industry to participate from locations throughout the southwest region. The participants were able to hear presentations on critical issues related to carbon sequestration and interact with speakers and each other during the event. The Centra system also made it possible for representative members of the Southwest Regional Partnership to meet on-line during the planning processes, eliminating considerable time and expense for travel.

A second on-line town hall meeting is scheduled for December 16, 2004. Representatives of tribal/government agencies and non-government agencies will be invited to participate in this event. The CentraOne Symposium system provided by WERC will again be utilized for this event.

\section{Task 4: Identify and Rank Sequestration Options for the Southwest Region}

\section{Summary Discussion of Subtask 4.1}

\section{Summary of Year 1 Integrated Assessment Analysis}

The viability to sequester $\mathrm{CO}_{2}$ in the Southwest region (or any other region) depends on storage potential, $\mathrm{CO}_{2}$ production, gas transmission infrastructure, regional economic conditions, costs of potential sequestration technologies, and public understanding and acceptance of selected sequestration approaches. An integrated assessment framework is needed to allow a complete analysis that includes all these elements. As part of the Southwest Regional Partnership such an integrated assessment model is being developed (described in the section describing Subtask 2.4, above), based on Southwest region characteristics. The model will provide the capability to assess different regional sequestration options for different $\mathrm{CO}_{2}$ emissions sources, and to evaluate the $\mathrm{CO}_{2}$ emissions in the region to 2025 .

In the absence of action, total annual $\mathrm{CO}_{2}$ emissions in the Southwest Partnership region are expected to rise from 500 million tons in 2001 to about 750 million tons by 2012. The region has an opportunity to offset much of this emissions growth through various terrestrial, geologic, and mineralization sequestration options.

Environmental, economic, and social consequences are associated with each option. Quantifying these consequences is challenging because of the interrelationships that link the economy, energy consumption, population growth, $\mathrm{CO}_{2}$ emissions, and other environmental 
impacts. The objective of the Integrated Assessment Committee and its analyses is to establish a framework for establishing and communicating the consequences and tradeoffs between alternative $\mathrm{CO}_{2}$ emission reduction strategies, which is a necessary first step in formulating an effective and publicly acceptable sequestration program. Public perceptions are being addressed through a series of workshops where participants will be given access to the integrated assessment model to determine if it captures the important sequestration issues, and to increase understanding of the tradeoffs between different sequestration approaches.

The ultimate outcome of this integrated assessment analysis is to provide an equitable and semi-quantitative to quantitative comparison of all Phase II options, summarized in the Executive summary of this report. Such a comparison is essential to provide a means for ranking the options and developing action plans for carrying out the Phase II pilot project. We anticipate completing the assessment and ranking process during the next several months, including development of associated action plans.

\section{Conclusions}

The Southwest Partnership on Carbon Sequestration comprises a large, diverse group of expert organizations and individuals specializing in carbon sequestration science and engineering, as well as public policy and outreach. The Partnership has made significant progress in this first year, and is "on schedule" with all tasks and objectives.

Possible Phase II opportunities, including approaches and sites, have been identified and are being evaluated. Specifically, the Partnership will likely propose to carry out one or two major geologic sequestration pilot tests, as well as a secondary terrestrial pilot evaluation that will possibly focus on the unique surface vegetation attributes of the region. Possible geologic pilot sites include areas in the four corners region (confluence of Utah, Colorado, New Mexico, and Arizona borders), northern Oklahoma, western Texas, and southern Wyoming.

Action plans for possible Phase II carbon sequestration pilot tests in the region are almost finished, including both technical and non-technical aspects necessary for developing and carrying out these pilot tests. All partners in the Partnership are taking an active role in evaluating and ranking optimum sites and technologies for capture and storage of $\mathrm{CO}_{2}$ in the Southwest Region. We are identifying potential gaps in all aspects of potential sequestration deployment issues.

The general approach for Phase II action plans taken by the Partnership is to focus on a "testcase” area, including two counties, for which all working groups are focusing their efforts on these two counties (one in NM, one in CO, to account for interstate aspects). This test-case evaluation is permitting development of a "template" evaluation that we will use to analyze all Phase II possibilities on an equitable/parity basis. After all Phase II options are evaluated and compared, this evaluation "template" will be used to analyze remaining sequestration target areas in the region, such that the comprehensive regional results and database will be available for developing future sequestration opportunities.

\section{References}

Allis, R., Bergfeld, D., Moore, J., Chidsey, T., Morgan C., McClure, K., Heath, J., and McPherson, B. (2004): Soil gas $\mathrm{CO}_{2}$ flux measurements over the natural $\mathrm{CO}_{2}$ systems of 
Farnham Dome, Utah, Crystal-Ten Mile Geyser area, Utah, and Springerville, Arizona; manuscript in prep.

Benson, S. M. and Myer, L. (2002): Monitoring to ensure safe and effective geologic sequestration of carbon dioxide, Proceedings of IPCC workshop on carbon dioxide capture and storage, 2002.

Daniels, S. E., \& Walker, G. B. (2001). Working through environmental conflict: The Collaborative Learning Approach. Westport, Connecticut: Praeger.

Hendrickx, J.M.H., Phillips, F.M., Harrison, J.B.J. (2003): Water flow processes in arid and semi-arid vadose zones.” In Understanding water in a dry environment: hydrological processes in arid and semi-arid zones (Ed. Ian Simmers). IAH International Contributions to Hydrogeology 23, AA Balkema, Netherlands.

Heath, J. (2004): Hydrogeochemical Characterization of Leaking Carbon Dioxide-Charged Fault Zones in East-Central Utah, M.S. Thesis, Utah State University, 176 pp.

Heath, J. and McPherson, B. (2004): 2-D Numerical Modeling of a Fault Zone Leaking Carbon Dioxide in East Central Utah, paper accepted for presentation at American Geophysical Union Fall Meeting, San Francisco, December.

Kinsella, W. J. (2004). Public expertise: A foundation for citizen participation in energy and environmental decisions. In S. P. Dopoe \& J. W. Delicath \& M.-F. A. Elsenbeer (Eds.), Communication and Public Participation in Environmental Decision Making (pp. 83-98). Albany, New York: State University of New York Press.

Klusman, R.W. (2003): Rate measurements and detection of gas microseepage to the atmosphere from an enhanced oil recovery/sequestration project, Rangely, Colorado, USA. App. Geochem., 18, 1825-1838.

Moore, J., Adams, M., Allis, R., Lutz, S., Rauzi, S. (2004): Mineralogical and geochemical consequences of the long term presence of $\mathrm{CO} 2$ in natural reservoirs: An example from the Springerville-St. Johns field, Arizona and New Mexico, U.S.A. Chemical Geology, in press

Oskarsson, N.K., Palsson, H. Olafsson, and T. Ferreira (1999): Experimental Monitoring of Carbon Dioxide by Low Power IR-Sensors; Soil Degassing in the Furnas Volcanic Centre, Azores, J. Volcanol. Geotherm. Res, 92, pp. 181-193m.

Rauzi, S.L. (1999): Carbon dioxide in the St Johns-Springerville area, Apache County, Arizona. Arizona Geological Survey Open-File Report 99-2.

Sorey, M.L., C.D. Farrar, W.C. Evans, D.P. Hill, R.A. Bailey, J.W. Hendley II, and P.H. Stauffer (1996): Invisible CO2 Gas Killing Trees at Mammoth Mountain, California, U.S. Geological Survey Fact Sheet, pp. 172-196, http://quake.wr.usgs.gov/prepare/factsheets/CO2 /. 